Article

\title{
Selective Laser Melting Heat Sinks under Jet Impingement Cooling for Heat Dissipation of Higher Light Output LED Lighting in a Limited Space
}

\author{
Yi-Cheng Huang * (D) and Huan-Chu Hsu \\ Department of Mechatronics Engineering, National Changhua University of Education, \\ Changhua 50074, Taiwan; george7519@gmail.com \\ * Correspondence: ychuang@cc.ncue.edu.tw
}

Received: 28 April 2020; Accepted: 2 June 2020; Published: 4 June 2020

check for updates

\begin{abstract}
In this study, we aimed to create heat sinks with higher heat dissipation capabilities for a compact light-emitting diode (LED) recessed downlight (CLRDL) under jet impingement cooling. We desired to use the sinks in limited space to maintain lower junction temperature and allow higher LED power. Perforated-finned heat sinks (PTFHSs) and metal-foam-like heat sinks (MFLHSs) fabricated using selective laser melting (SLM) were compared with a traditional finned heat sink (TTFHS). Two cooling fans with higher and lower velocity at Reynolds numbers of 16916 and 6594 were individually installed on each heat sink. Numerical simulations were performed using COMSOL rotating machinery and nonisothermal flow interface with the standard $k-\varepsilon$ turbulence flow model. Validations were performed on this apparatus. The SLM heat sinks exhibited higher Nusselt numbers and lower thermal resistance than traditional heat sinks because of a relatively higher heat transfer coefficient and larger heat transfer area. For the proposed SLM heat sinks with larger surface areas, complex flow channels, and ventilation holes under jet impingement cooling, the PTFHS exhibited the highest heat transfer enhancement followed by MFLHS and TTFHS. The results contribute to solving the problems of heat dissipation of higher light output LED lighting.
\end{abstract}

Keywords: LED lighting; forced convection; air jet impingement cooling; heat sink; selective laser melting; numerical simulation

\section{Introduction}

Over past several years, rapid advancement has been observed in light-emitting diode (LED) technology. LEDs are now being widely used in residential, commercial, and industrial applications. However, for LEDs, high light output is characterized by more heat. Therefore, thermal management is necessary. Downlights with LED power more than $24 \mathrm{~W}$ and light output more than 2000 lumens are now being successfully developed in the market. However, heat sinks with thermal management that relies on nature convection are often heavier and bulkier. In many applications, the device requires extremely high light output but the allowable installation space for the LED lamp is limited. This motivates a compact heat sink with enhanced thermal removal performance.

The objectives of this study are to solve the aforementioned problems through the following procedures: (1) to perform simulation and experimental validation to predict the fluid flow and heat dissipation performance characteristics of the designed heat sinks. A traditional heat sink was used as a benchmark to compare various geometries of selective laser melting (SLM)-fabricated heat sinks for compact LED recessed lighting. (2) To study the effects of changing flow velocity for evaluating heat sink performances under turbulent flow conditions. (3) To investigate the SLM-fabricated heat sinks that provide relatively higher Nusselt numbers and lower thermal resistance than traditional heat sinks under jet impingement cooling. 
Traditionally, air jet impingement cooling is recognized for its high heat transfer rates (i.e., when the temperatures of the impinging jet flow are different from that of the impingement surface). The Reynolds number increases with increasing inlet velocity of air jet impingement. Based on a literature review and our empirical analysis, a higher Reynolds number flow indicates a higher heat transfer rate than that at lower Reynolds number. Therefore, increasing inlet velocity is a vital approach to remove heat from the thermal device. Air jet impingement cooling in a confined space is generated using a cooling fan, which functions as a rotating machinery device. To accurately simulate heat dissipation performance of heat sinks under jet impingement cooling in a turbulent flow field, we used the COMSOL Multiphysics rotating machinery, nonisothermal flow interface with a standard $k-\varepsilon$ turbulence flow model, and the frozen rotor study type (COMSOL Inc., Burlington, MA, USA 2017) [1].

Several studies have investigated the $k-\varepsilon$ turbulence model and heat transfer characteristics of air jet impingement on heat sinks. The standard $k-\varepsilon$ model with realizability constraints is widely used in industrial modeling tools and applications and provides robust and reasonably accurate prediction. The model performs satisfactorily in solving the external flow problems of complex geometries. Li et al. (2007) [2] investigated the heat transfer of plate-fin heat sinks under impinging jet cooling. The standard $k-\varepsilon$ turbulent model was used to perform the simulation. Their simulation results were validated using experimental data. The results indicated that heat removal increases with increasing Reynolds number. Yang et al. (2013) [3] performed a numerical investigation for the turbulent fluid flow and heat transfer characteristics of air jet impingement onto the rotating and stationary heat sink by using four different turbulent models based on Reynolds-averaged Navier-Stokes (RANS) equations. The results of the study indicated that the standard $k-\varepsilon$ model provides better predictions for fluid flow and heat transfer performance. Therefore, in this study, we performed numerical simulations for evaluating the heat dissipation performance of heat sinks for CLRDLs using standard $k-\varepsilon$ turbulence models based on the Reynolds-averaged Navier-Stokes equations.

In recent years, additive manufacturing (AM) technology has gained increasing attention and has been applied in industries and academic research because AM substantially increases the design freedom for lattice structure shaping and high material usage efficiency. Furthermore, AM technology offers near net shape manufacturing of light components used in industrial applications. The AM process is a powerful tool for the production of complex parts, whose fabrication is difficult using traditional manufacturing techniques such as internal cooling channels or a large number of ventilation holes. Furthermore, AM provides rapid prototype production for the development of new products, multiple-model production, and short time-to-market. Additive manufacturing describes a number of additive processes, the most popular AM processes such as laser based powder bed fusion, including SLM, selective laser sintering (SLS), and direct metal laser sintering (DMLS) are now available.

Collins et al. (2019) [4] proposed and experimentally evaluated a novel permeable membrane microchannel (PMM) heat sink design. The AlSi10Mg aluminum alloy fabricated by DMLS was used to produce the features with complex and thin porous wall to overcome the pressure drop issues. The AlSi10Mg with a nominal conductivity of $k$ was considered as approximately $110 \mathrm{~W} \mathrm{~m}^{-1} \mathrm{~K}^{-1}$. The fluids flow to the heat sink was forced through thin porous walls which was functioned as conducting fins and membranes with fine internal flow heat convection that enables throughflow for efficient heat exchange. A low-pressure-drop manifold microchannel (MMC) heat sink was used as benchmark for evaluating the performance of the PMM heat sink geometry. Both heat sinks were experimentally characterized using deionized water as the working fluid at a constant pumping power of $0.018 \mathrm{~W}$ and flow rates of $50-500 \mathrm{~mL} \mathrm{~min}^{-1}$, the permeable membrane microchannel design delivered a $17 \%$ reduction in thermal resistance and a $28 \%$ reduction in pressure drop compared to the MMC.

The AlSi10Mg is an aluminum-based alloy that is widely used in the AM-fabricated products requiring better mechanical properties and high thermal conductivity. The thermal conductivity $(k)$ of solid AlSi10Mg at 20 and $100{ }^{\circ} \mathrm{C}$ is 147 and $155 \mathrm{~W} \mathrm{~m}^{-1} \mathrm{~K}^{-1}$, respectively, and the specific heat capacity $\left(C_{\mathrm{p}}\right)$ at 20 and $100{ }^{\circ} \mathrm{C}$ is 739 and $755 \mathrm{~J} \mathrm{~kg}^{-1} \mathrm{~K}^{-1}$, respectively. The density $(\rho)$ of solid AlSi10Mg is $2650 \mathrm{~kg} \mathrm{~m}^{-3}$ ( $\mathrm{Li}$ and $\mathrm{Gu}$ 2014) [5]. Kempen et al. (2012) [6] revealed that SLM is an additive 
manufacturing technique. In this technique, a part is fabricated layer wise by melting the top layer of a powder bed by using a high intensity laser that uses sliced 3D CAD data. The mechanical properties of SLM-produced AlSi10Mg parts, such as tensile strength, elongation, Young's modulus, impact toughness, and hardness were studied. These parts are comparable or superior to conventionally produced AlSi10Mg cast parts. However, AlSi10Mg thermal performance was not presented. Huang and Chen (2014) [7] studied an optimal heat sink design problem, in which nonuniform fin widths and heights were used to minimize the system thermal resistance $(R)$ of the fin array and obtain the optimal dimensions of the heat sink. Under forced convection, heat dissipation results in heat removal when the circulation flow passage design is appropriate. Ong et al. (2017) [8] studied two-finned heat sink performance. The performance of two conventional finned heat sinks was examined under air cooling with forced and natural convections and using different heating power inputs. They determined fin temperatures and heat transfer coefficients for heating elements of different sizes producing different area aspect ratios.

Furthermore, the surface-to-volume ratio in traditional fin heat sinks is high, which generates relatively complex fin shapes. An increase in the surface-area-to-volume ratio increases the heat transfer surface area. However, the channels of the tortuous flow path relatively decrease with increasing surface-area-to-volume ratio, and thus, increase heat sink flow resistance. Therefore, determining an appropriate fluid flow channel, ventilation holes, and height for heat sinks is essential. The limited installation space of the LED lamp results in optimized dimensions and geometries of PTFHS and MFLHS heat sinks fabricated using AlSi10Mg alloy are shown in Figure 1.

(a1)

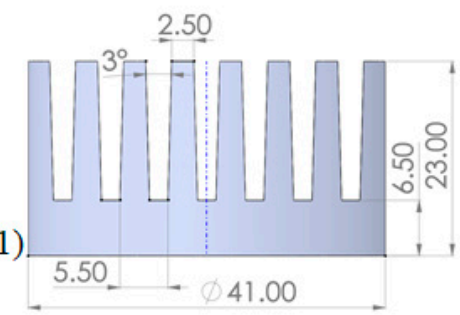

(a2)

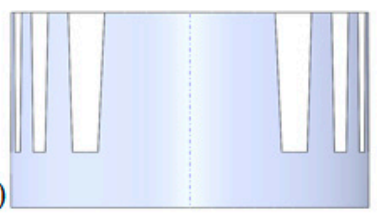

(a3)

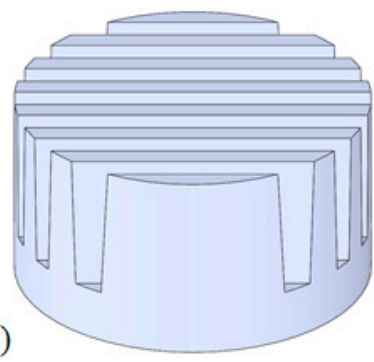

(b3)

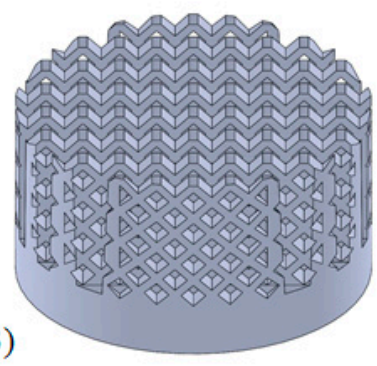

(b1)

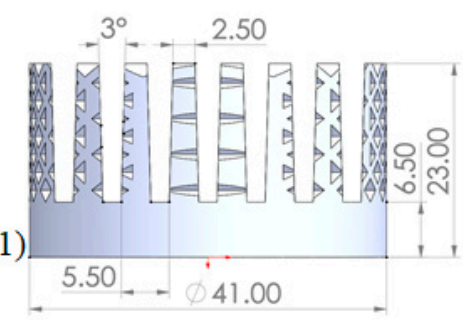

(b2)

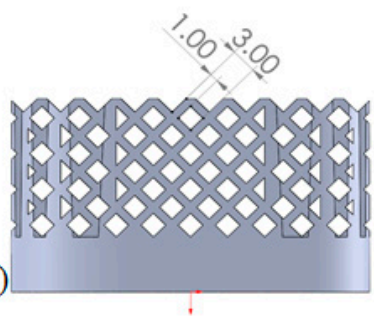

(c1)

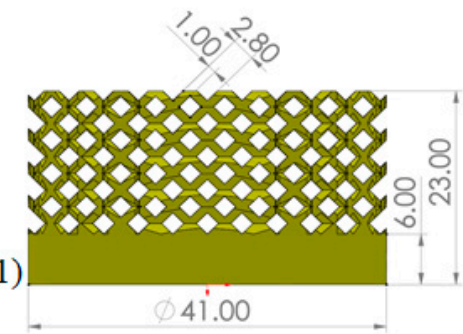

(c2)

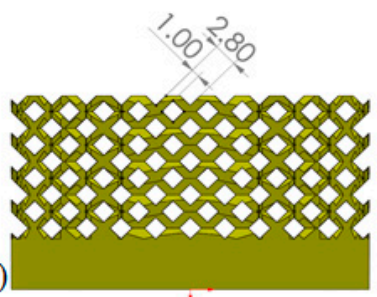

(c3)

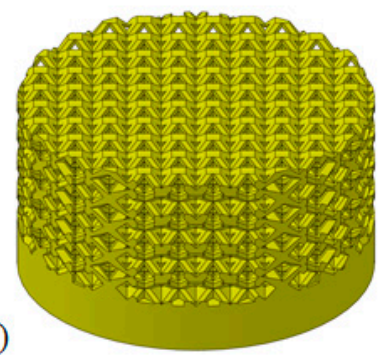

Figure 1. The geometry designs for TTFHS (a1)-(a3), PTFHS (b1)-(b3), and MFLHS (c1)-(c3). 
The performance of impingement heat sink designs and the heat transfer capabilities of the designed heat sinks under jet impingement cooling with different Reynolds numbers was examined in this study. Heat sinks with larger surface areas for heat transfer and perforated heat sinks with ventilation holes were studied through simulations and experiments. In the experiments, the perforated-finned heat sinks (PTFHS), metal-foam-like heat sinks (MFLHS), and traditional finned heat sink (TTFHS) were individually mounted to a $10 \mathrm{~W}$ compact LED recessed downlight (CLRDL) at an ambient temperature of $25^{\circ} \mathrm{C}$. A cooling fan was installed on the top of each heat sink, and two cooling fans with higher and lower velocities of 6.13 and $2.71 \mathrm{~m} \mathrm{~s}^{-1}$ were individually installed to perform air jet impingement cooling evaluations. This ensures that the CLRDL had a very low $T_{\mathrm{j}}$, which satisfied the long lifetime requirement.

The previous studies (Hsu and Huang 2016; Huang and Hsu 2018) [9,10] have validated that the use of PTFHS, MFLHS, and TTFHS for cooling a CLRDL under natural convection complied with Energy Star lifetime requirements. High-power heat dissipation of LED lighting for state-of-the-art heat sinks is one of the foremost requirements in the recent emerging era. The high heat dissipation capability using fans enables superior cooling performance for the high-power LED module, in which high luminous flux indoor lighting or extremely high intensity light source for automated optical inspection equipment are requisites. Therefore, investigation of the SLM heat sink heat transfer performance when the additional fan is introduced should be conducted. Figure 2 illustrates the flowchart of the numerical simulations and experiments on designing the PTFHS, MFLHS, and TTFHS heat sinks under jet impingement cooling for (CLRDLs. Due to the created forced convection turbulence flow, increasing surface area through mixed cooling convection and the ensemble interactive effect between perforated holes of heat sinks should prevail and dominate the CLRDL market. These applications require extremely high light output in a limited space.

In the following sections, we include the research procedure, numerical simulation, followed by experiments. Results demonstrate the advantages of heat transfer of the PTFHS and MFLHS SLM heat sinks over conventional TTFHS under air jet impingement cooling. Enhanced heat transfer techniques result in lower LED junction temperature and increase the CLRDL lifetime and reliability.

\subsection{Research Procedure}

A flowchart of numerical simulations and experiments for achieving lower LED junction temperature with the increasing demand of higher LED power is depicted in Figure 1 for CLRDL confined in a limited space.

\subsection{Geometric Design of Heat Sinks}

TTFHS, PTFHS, and MFLHS geometrics are presented in Figure 2 (dimensions are in $\mathrm{mm}$ ). The dimensions of the heat sinks were based on previous study (Hsu and Huang 2016; Huang and Hsu 2018) $[9,10]$. The overall height of the TTFHS, PTFHS, and MFLHS were fixed at $23 \mathrm{~mm}$ for the confined space. Figure 2 displays the geometries of TTFHS (a1)-(a3), PTFHS (b1)-(b3), and MFLHS (c1)-(c3), where (a1)-(c1), (a2)-(c2), and (a3)-(c3) indicate the front, side, and isometric views, respectively. The TTFHS was fabricated using a traditional metal cast manufacturing process, whereas the PTFHS and MFLHS were fabricated using the SLM process. 


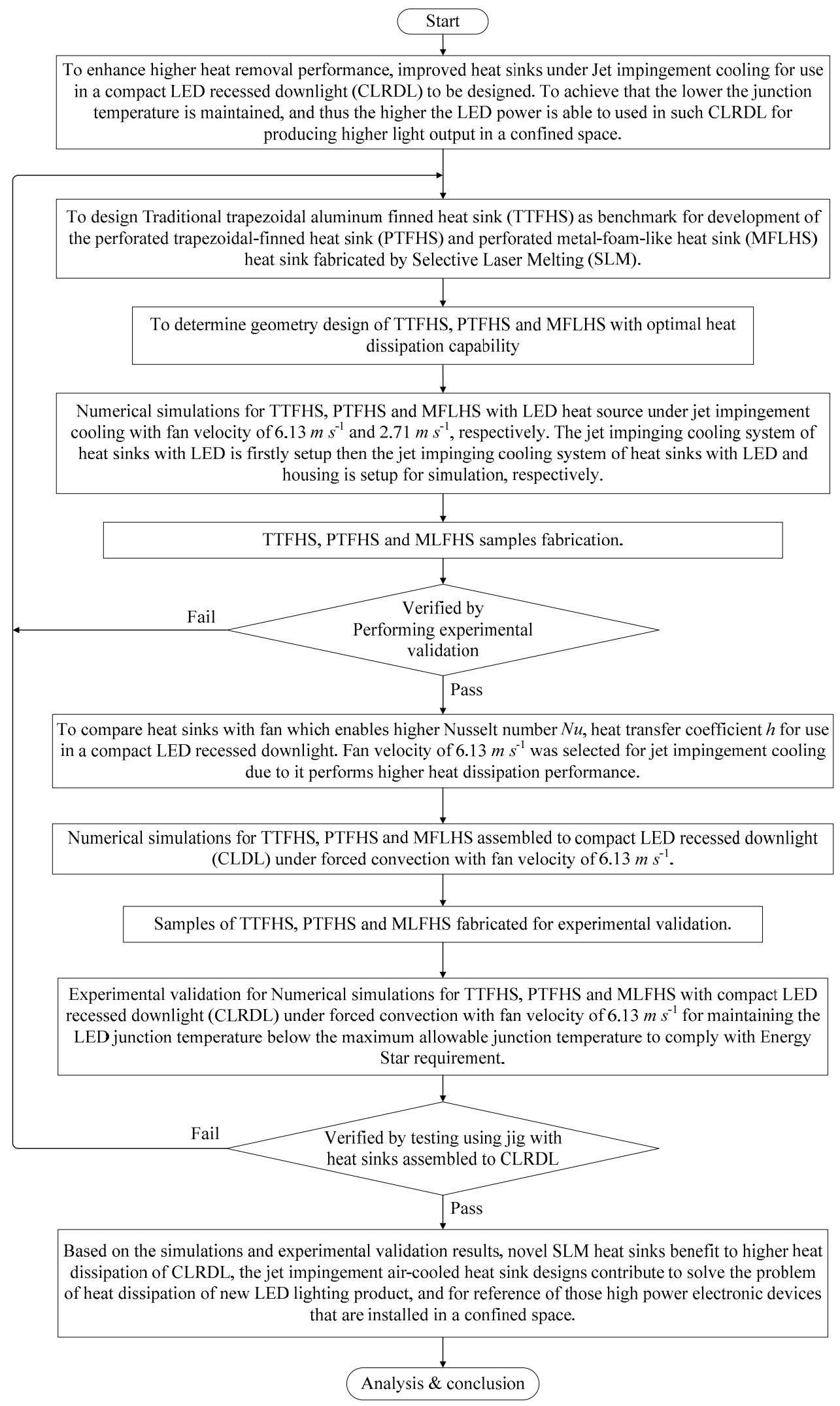

Figure 2. Flowchart of the numerical simulations and experiments on designing the heat sinks of a traditional finned heat sink (TTFHS), perforated-finned heat sink (PTFHS), and metal-foam-like heat sink (MFLHS) under jet impingement cooling for compact light-emitting diode (LED) recessed downlights (CLRDLs). 


\section{Mathematical Formulation}

\subsection{Governing Equations and Numerical Models}

Figure $3 a, b$ presents the dimensions of the cylindrical computational domain for heat sinks with LED and heat sinks with LED and housing, respectively. The air jet impingement cooling in a confined area is generated using a cooling fan, which functions as a rotating machinery device. Version 5.3 of COMSOL Multiphysics software (COMSOL Inc., Burlington, MA, USA) is used for geometry modeling, grid meshing, physics modeling, solving, and post processing to simulate the results (COMSOL Inc. 2017) [1]. To accurately simulate heat sink heat dissipation performance under jet impingement cooling, the rotating machinery is coupled with nonisothermal flow interface with a standard $k-\varepsilon$ turbulence flow model to examine the heat transfer in the turbulent flow field. Typically, the continuity equation governs mass conservation, and the Navier-Stokes equations govern the momentum balance. The rotating parts are kept frozen in position, and rotation is accounted for by the effects of the Coriolis and centrifugal forces. Thus, the numerical simulated rotating flow is fixed or frozen by assuming that the topology of the system relative to the rotating reference frame. This saves considerable computation time and resources for simulating the pseudo stationary formulation.

The quasi-steady flow is computed with the interface of the rotating machinery. The axial, tangential, and radial flow velocity components can be simulated for numerical and experimental validation when the flow exits the round tube. Nonisothermal flow occurs in this CLRDL through temperature gradient (COMSOL Inc. 2017) [1]. The turbulent three-dimensional Navier-Stokes and energy equations negligible radiative heat transfer are numerically solved using computational fluid dynamics.

The governing differential equations of continuity, momentum, and energy are as follows:

$$
\begin{gathered}
\frac{\partial \rho}{\partial t}+\nabla \cdot(\rho \boldsymbol{u})=0 \\
\rho \frac{\partial \boldsymbol{u}}{\partial t}+\rho \boldsymbol{u} \cdot \nabla \boldsymbol{u}=-\nabla p+\nabla \cdot\left[\mu\left(\nabla \boldsymbol{u}+(\nabla \boldsymbol{u})^{T}\right)-\frac{2}{3} \mu(\nabla \cdot \boldsymbol{u}) \boldsymbol{I}\right]+\boldsymbol{F}
\end{gathered}
$$

where $u$ is the velocity vector, superscript $T$ is the transpose of matrix, $p$ is the pressure, $\mu$ is the dynamic viscosity of the air, $I$ is the identity matrix, and $F$ is the volume force vector.

The $k$-cturbulence model provides two additional transport equations for two dependent variables, which incorporates the turbulent kinetic energy, $k$, and the dissipation rate of turbulent kinetic energy, $\varepsilon$.

The turbulent viscosity is expressed as follows:

$$
\mu_{T}=\rho C_{\mu} \frac{k^{2}}{\varepsilon}
$$

where $C_{\mu}$ is a model constant.

The transport equation for the turbulent kinetic energy $k$ is as follows:

$$
\rho \frac{\partial k}{\partial t}+\rho \boldsymbol{u} \cdot \nabla k=\nabla \cdot\left[\left(\mu+\frac{\mu_{T}}{\sigma_{\mathrm{k}}}\right) \nabla k\right]+P_{\mathrm{k}}-\rho \varepsilon
$$

where the production term is defined as follows:

$$
P_{k}=\mu_{\mathrm{T}}\left[\nabla \boldsymbol{u}:\left(\nabla \boldsymbol{u}+(\nabla \boldsymbol{u})^{T}\right)-\frac{2}{3}(\nabla \cdot \boldsymbol{u})^{2}\right]-\frac{2}{3} \rho k \nabla \cdot \boldsymbol{u}
$$

The evolution of the dissipation rate of the turbulent kinetic energy, $\varepsilon$, is determined by the following expression:

$$
\rho \frac{\partial \varepsilon}{\partial t}+\rho \boldsymbol{u} \cdot \nabla \varepsilon=\nabla \cdot\left[\left(\mu+\frac{\mu^{T}}{\sigma_{\varepsilon}}\right) \nabla \varepsilon\right]+C_{\varepsilon 1} \frac{\varepsilon}{k} P_{k}-C_{\varepsilon 2} \rho \frac{\varepsilon^{2}}{k}
$$


The corresponding model constants for turbulence flow of the $k-\varepsilon$ turbulence model are denoted by the following values: $C_{\mu}=0.09, C_{\varepsilon 1}=1.44, C_{\varepsilon 2}=1.92, \sigma_{\mathrm{k}}=1.0, \sigma_{\varepsilon}=1.3$.

Convective and conductive heat transfer is governed by the following equation:

$$
\rho C_{\mathrm{p}} \frac{\partial T}{\partial t}+\rho C_{\mathrm{p}} \boldsymbol{u} \cdot \nabla T=\nabla \cdot(k \nabla T)+Q
$$

\subsection{Numerical Computations}

The Reynolds number of the jet impinging is expressed as follows:

$$
R e=\frac{\rho u D}{\mu}
$$

To objectively represent which of the extended surfaces of heat sinks is able to transfer the most heat, a modified convective heat transfer coefficient is used as follows (Wong et al. 2009) [11]:

$$
h_{\mathrm{m}}=\frac{Q}{A_{\mathrm{b}}\left(T_{\mathrm{b}}-T_{\mathrm{jet}}\right)}
$$

where $A_{\mathrm{b}}$ is the surface area of the heat sink base by $1320 \mathrm{~mm}^{2}$. The modified heat transfer coefficient in Equation (9), which benefits heat sinks with smaller surface areas, was used instead of the commonly used heat transfer over the surface area for improving the heat transfer performance (Wong et al. 2009) [11]. The $h_{\mathrm{m}}$ is adopted as conventional $h$ for denoting the convective heat transfer coefficient. The average temperature $T_{\mathrm{b}}$ of each heat sink is calculated from $T_{\mathrm{b} 1}$ and $T_{\mathrm{b} 2}$ by using Equation (10) as shown in Figure 3a.

$$
T_{\mathrm{b}}=\frac{T_{\mathrm{b} 1}+T_{\mathrm{b} 2}}{2}
$$

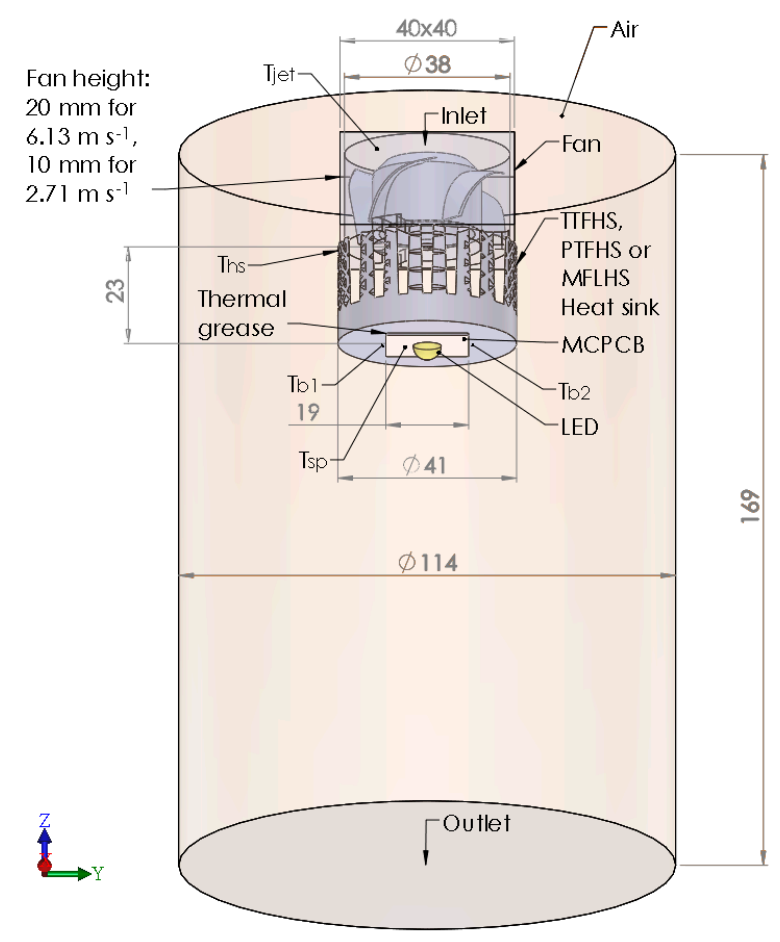

(a)

Figure 3. Cont. 


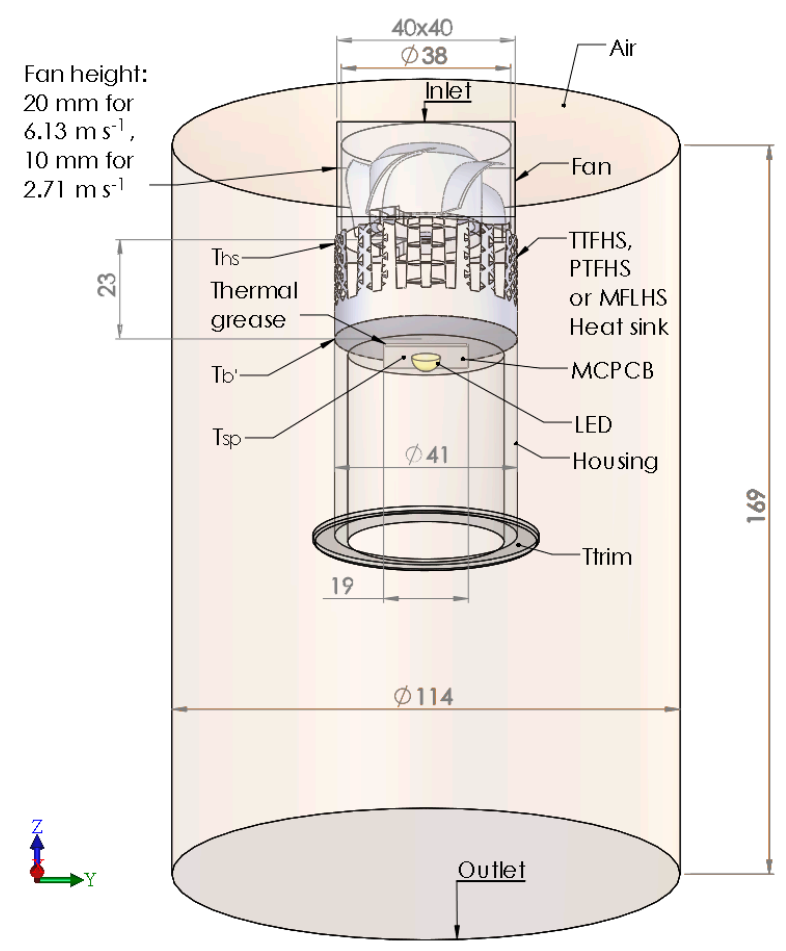

(b)

Figure 3. Isometric view of computational domain for the jet impinging cooling system, (a) heat sinks with LED, (b) heat sinks with LED and housing.

To evaluate the heat dissipation performance of the heat sinks, the Nusselt number is used. The Nusselt number based on the inlet jet hole diameter is given by Equation (11).

$$
N u=\frac{h_{\mathrm{m}} D}{k}=\frac{q^{\prime \prime}}{T_{\mathrm{b}}-T_{\mathrm{jet}}} \cdot \frac{D}{k}
$$

The rotation equations of the machinery are expressed as follows (COMSOL Inc. 2017) [1]:

$$
\begin{aligned}
& d x=d x\left(r_{b p}, \omega, t^{*}\right) \\
& \frac{d w}{d t}=w(t) \\
& \omega=w t^{*}=-2 \pi f, t^{*}=\text { Frozen time }
\end{aligned}
$$

where $x$ denotes a point position in the coordinate system, $f$ is frequency.

\section{Numerical Simulation Modeling}

Numerical simulation was conducted for three different geometric types of heat sinks (MFLHS, PTFHS, and TTFHS) under jet impingement cooling at higher and lower Reynolds numbers. The investigation scheme is tabulated in Table 1. Based on literature reviews and our observation, a higher Reynolds number flow exhibits higher heat transfer performance than a lower Reynolds number flow. Therefore, only the fan velocity of $6.13 \mathrm{~m} \mathrm{~s}^{-1}$ with a higher Reynolds number was selected for cases 7-9 of the experimental setup for the CLRDL, which incorporated the heat sink with LED and housing.

The jet impinging cooling system of heat sinks with LED was investigated to obtain a modified convective heat transfer coefficient $\left(h_{\mathrm{m}}\right)$, Nusselt number $(\mathrm{N} u)$, and thermal resistance $\left(R_{\mathrm{sp} \text {-jet }}\right)$ of heat sinks with LED from $T_{\mathrm{sp}}$ to $T_{\text {jet }}$ without housing. Furthermore, the jet impinging cooling systems of heat sinks with LED and housing were investigated for the overall thermal resistance $\left(R_{\text {sp-jet }}\right)$ of heat 
sinks from $T_{\text {sp }}$ to $T_{\text {jet }}$ for the CLRDL. The same investigation scheme was used to obtain the convective heat transfer coefficient, Nusselt number, and thermal resistance of heat sinks with housing.

In Figure 3 (dimensions are in mm), modeling and analysis process for PTFHS as a representative example are as follows: the jet impinging cooling system of heat sinks with LED is first set up (Figure 3a), and then the jet impinging cooling system of heat sinks with LED and housing is set up (Figure 3b) for simulation.

Mechanism of using COMSOL Multiphysics module is the rotating machinery with nonisothermal flow function by which the physical model includes RANS for turbulence mode type, the $k-\varepsilon$ flow for turbulence model; and the frozen-rotor study type are adapted into the simulation. Especially, the frozen-rotor study is a modeling approach which treats the rotor as fixed, or frozen in space. The flow in the rotating domain is assumed to be stationary based on a rotating coordinate system. The flow in the non-rotating parts is also assumed to be stationary, but in a non-rotating coordinate system (COMSOL Inc. 2017) [1]. This numerical model is validated by comparing the numerical simulation first and experimental results thereafter in this study.

Table 1. The investigation scheme.

\begin{tabular}{cccc}
\hline Case & Testing Method & Velocity of $\mathbf{6 . 1 3} \mathbf{~ m ~ s}^{-\mathbf{1}}$ & Velocity of $\mathbf{2 . 7 1} \mathbf{~ m ~ s}^{\mathbf{- 1}}$ \\
\hline 1 & TTFHS heat sinks with LED & $\bullet$ & \\
2 & PTFHS heat sinks with LED & $\bullet$ & \\
3 & MFLHS heat sinks with LED & & \\
4 & TTFHS heat sinks with LED & & \\
5 & PTFHS heat sinks with LED & & \\
6 & MFLHS heat sinks with LED & \\
7 & TTFHS heat sinks with LED and housing & $\bullet$ \\
8 & PTFHS heat sinks with LED and housing & $\bullet$ \\
9 & MFLHS heat sinks with LED and housing & & \\
\hline
\end{tabular}

\subsection{Grid Generation (Meshing)}

A fine resolution for a fluid flow model is required for convergence. With a wall function and no-slip condition, the flow over the solid surface for the standard $k-\varepsilon$ model can deliver a sufficiently accurate result at a considerably lower computational cost. Typical grid meshing is achieved using size parameters for free tetrahedral with a fine mesh. Elements with maximum element size, minimum element size, maximum element growth rate, curvature factor and resolutions of narrow regions were $0.0135 \mathrm{~m}, 0.00169 \mathrm{~m}, 1.45,0.5$, and 0.6 , respectively in this study.

\subsection{Boundary Conditions}

Table 2 lists the assumptions and summary of boundary conditions using cooling fan with a velocity of 6.13 and $2.71 \mathrm{~m} \mathrm{~s}^{-1}$ used for numerical simulations and calculations for heat sinks.

Table 2. Boundary conditions using cooling fan with velocity of $6.13 \mathrm{~m} \mathrm{~s}^{-1}$ and $2.71 \mathrm{~m} \mathrm{~s}^{-1}$.

\begin{tabular}{|c|c|c|c|}
\hline Fan Velocity of $6.13 \mathrm{~m} \mathrm{~s}^{-1}$ & Fluid Condition & Thermal Condition & Rotating Fan Condition \\
\hline Inlet & $\begin{array}{c}6.13 \mathrm{~m} \mathrm{~s}^{-1} \\
p=101.325 \mathrm{kPa}\end{array}$ & $T_{\text {jet }}=25^{\circ} \mathrm{C}$ & $\begin{array}{l}7200 \mathrm{rpm} \\
\text { Negative angular velocity }\end{array}$ \\
\hline Pressure outlet & $p=0 \mathrm{~Pa}$ & & \\
\hline Wall & Wall functions, no slip & & \\
\hline Boundary heat source from LED & & $Q=7.5 \mathrm{~W}$ & \\
\hline Fan velocity of $2.71 \mathrm{~m} \mathrm{~s}^{-1}$ & Fluid condition & Thermal condition & Rotating fan condition \\
\hline Inlet & $\begin{array}{c}2.71 \mathrm{~m} \mathrm{~s}^{-1} \\
p=101.325 \mathrm{kPa}\end{array}$ & $T_{\text {jet }}=25^{\circ} \mathrm{C}$ & $\begin{array}{l}2500 \mathrm{rpm} \\
\text { Negative angular velocity }\end{array}$ \\
\hline Pressure outlet & $p=0 \mathrm{~Pa}$ & & \\
\hline Wall & Wall functions, no slip & & \\
\hline Boundary heat source from LED & & $Q=7.5 \mathrm{~W}$ & \\
\hline
\end{tabular}




\section{Experiment Setup}

\subsection{Heat Sink Sample Fabrication}

PTFHS, MFLHS, and TTFHS as shown in Figure 4 were fabricated for experimental testing prior to experimental validation. The fabricated PTFHS, MFLHS, and TTFHS samples are illustrated in Figure $4 \mathrm{a}-\mathrm{c}$, respectively. The PTFHS and MFLHS consisted of the AlSi10Mg heat sinks fabricated through SLM. The TTFHS was fabricated using an aluminum die-casting material.

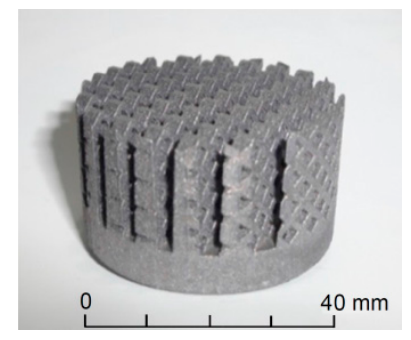

(a)

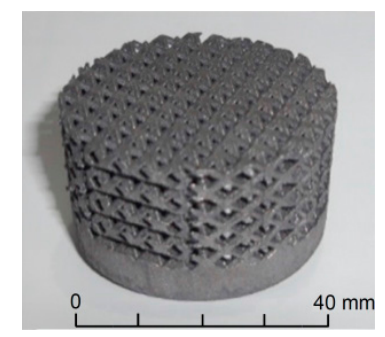

(b)

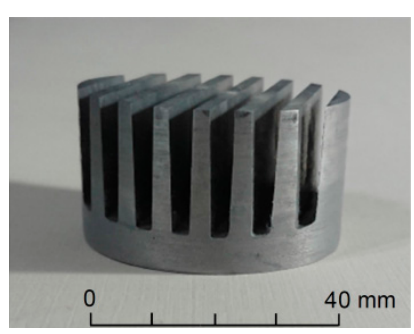

(c)

Figure 4. Heat sinks (a) PTFHS, (b) MFLHS, and (c) TTFHS.

\subsection{Experimental Setup and Procedure}

Figure $5 \mathrm{a}, \mathrm{b}$ presents the experiment setup for validating numerical simulations. Figure $5 \mathrm{a}$ depicts the experiment setup for the PTFHS with LED. Figure $5 \mathrm{~b}$ depicts the PTFHS with LED and housing in a clear acrylic cylinder test box with a $38 \mathrm{~mm}$ diameter inlet and a full opening outlet with a diameter of $140 \mathrm{~mm}$. The clear acrylic cylinder test box was used for jet impingement cooling. Air was blown at a constant temperature $\left(T_{\text {jet }}=25^{\circ} \mathrm{C}\right)$ and velocity into the test box from inlet hole by using a cooling fan. The cooling fan, heat sink, and LED module were assembled and mounted on the top wall of the cylinder test box using screws under inlet hole for evaluating heat sink performance. The experimental setup was the same as that of the computational domain that was used for numerical analysis. Prior to experimental testing, two cooling fans were used for generating higher and lower Reynolds number flow and tested using an anemometer. The test results indicated a flow velocity of 6.13 and $2.71 \mathrm{~m} \mathrm{~s}^{-1}$, respectively.

Each experiment conducted in Table 1 was under the same ambient temperature $25{ }^{\circ} \mathrm{C}$ for constant input current driver of the $10 \mathrm{~W}$ LED. The velocity of the fan is measured by an anemometer. The calibrated J-type thermocouples were attached to some specified temperature points that are connecting to a data acquisition device. The first step for case 1 is to turn on the data acquisition system, PC based computer, and the cooling fan. To power on the LED, temperatures of specified points such as $T_{\mathrm{sp}}, T_{\mathrm{b}}, T_{\mathrm{hs}}, T_{\text {jet }}$, and $T_{\text {trim }}$ will rise up naturally. Every thermocouple is recorded using the $34980 \mathrm{~A}$ Data Acquisition Unit (Agilent Technology). Experiment was conducting until the stable temperatures were reached. According to standard UL 8750 for LED, a temperature is considered stable if three successive readings, taken at $15 \mathrm{~min}$ intervals, are within $1{ }^{\circ} \mathrm{C}$ of one another and are still not rising. When case 1 is completed, similar cycles are completed for the rest of cases 2-9. The calculated steady state of heat transfer coefficients $(h)$, Nusselt number $(\mathrm{Nu})$, and heat sink thermal resistance $(R)$ for cases 1-6 are achieved and the thermal resistance $(R)$ for cases 7-9 with housing in practice were obtained thereafter.

The experimental setups under testing are illustrated in Figure 6. The figure illustrates the heat sink with LED under 6.13 and $2.71 \mathrm{~m} \mathrm{~s}^{-1}$ fan velocity when the fan height is 20 and $10 \mathrm{~mm}$, respectively. 


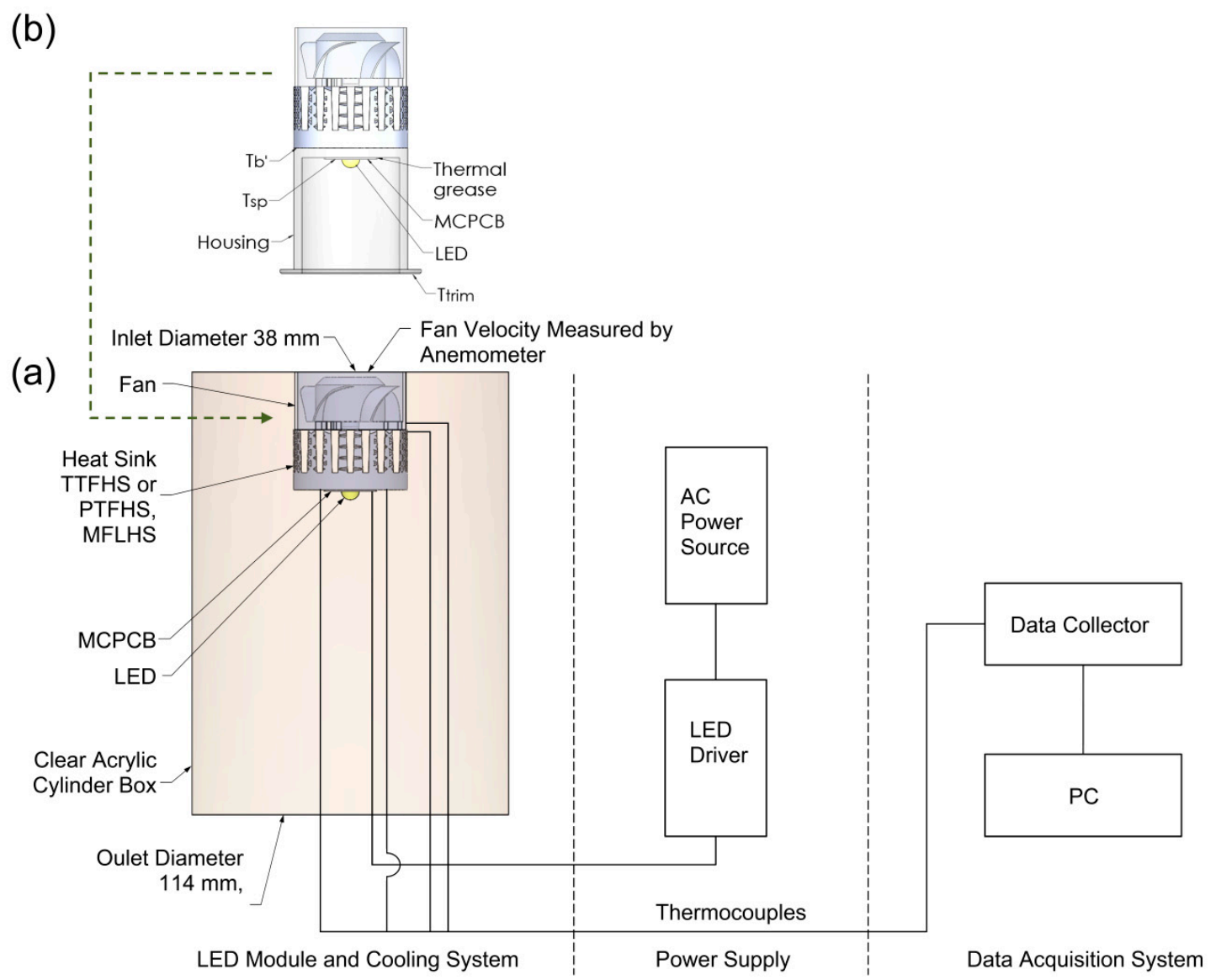

Figure 5. Schematic diagram of experimental setup for PTFHS with LED and housing. (a) Heat sinks with LED, (b) heat sinks with LED and housing.

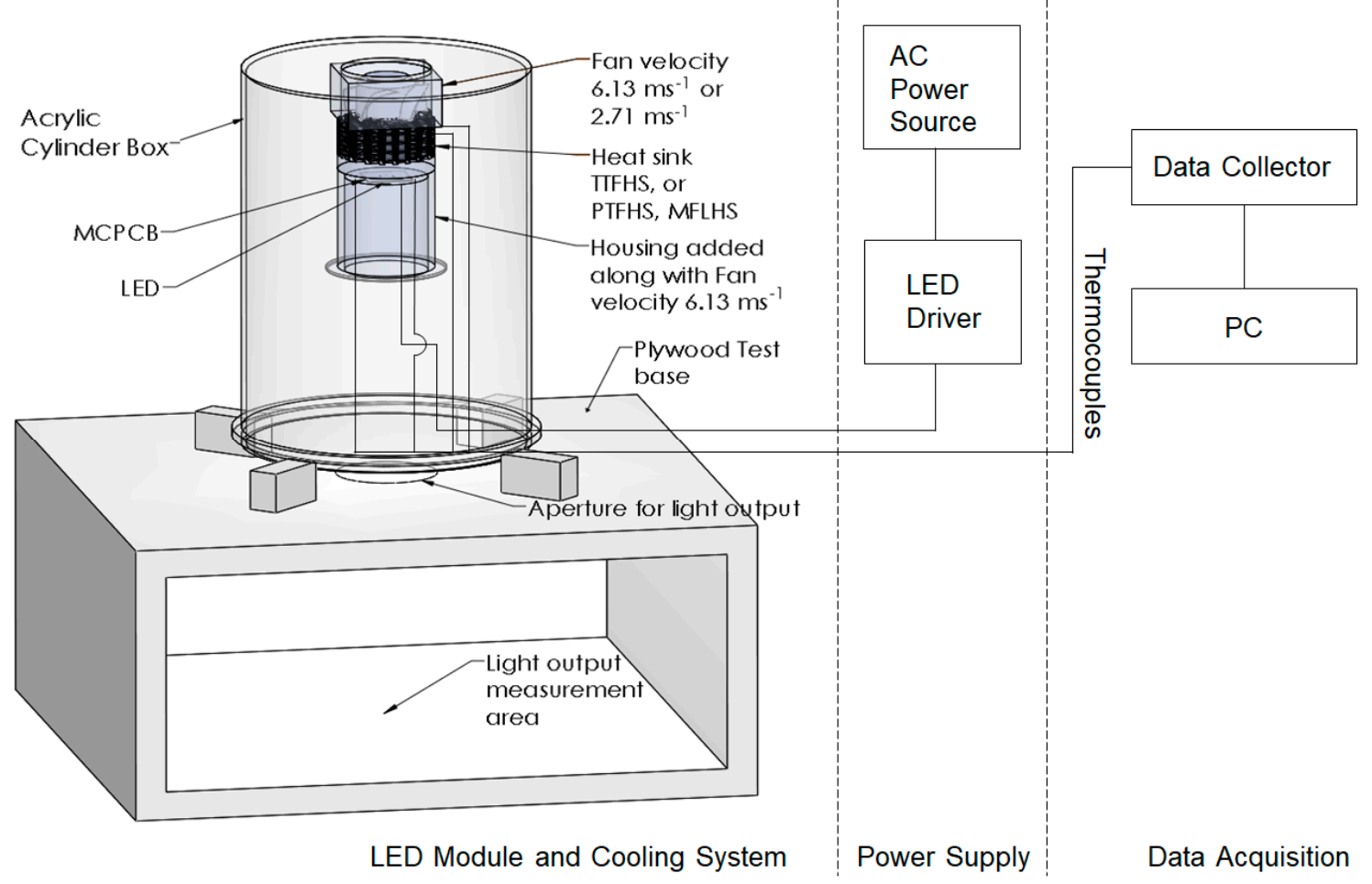

Figure 6. Illustrations of experimental setup under testing. 


\subsection{LED Junction Temperature and Thermal Resistance Calculation}

LED junction temperature and thermal resistance are calculated as following equations.

In Equation (13), the coefficient of thermal resistance $R_{\mathrm{j}-\mathrm{sp}}$ between $T_{\mathrm{j}}$ and $T_{\mathrm{sp}}$, according to the LED datasheet, was approximately $3.0 \mathrm{~K} \mathrm{~W}^{-1}$.

Equation (13) was used to calculate the LED $T_{\mathrm{j}}$ based on the measured $T_{\mathrm{sp}}$ and $Q$. Here, $Q$ is the heat generated by the LEDs. Approximately $75 \%$ of the input power $\left(V_{\mathrm{f}} \times I_{\mathrm{f}}\right)$ was treated as the output heat, whereas the remaining $25 \%$ of the input power was converted into light (Ahn et al. 2015) [12]. LED power dissipation $Q$ represents the heat rate for a heat transfer analysis

$$
T_{\mathrm{j}}=T_{\mathrm{sp}}+R_{\mathrm{j}-\mathrm{sp}} \cdot Q
$$

Individual thermal resistances $\left(R_{1-2}\right)$ can be calculated using Equation (14), where $T_{1}$ and $T_{2}$ denote the temperatures of nodes 1 and 2 , respectively.

$$
R_{1-2}=\frac{T_{1}-T_{2}}{Q}
$$

$T_{\mathrm{j}}-T_{\mathrm{jet}}$ is the temperature gradient or temperature drop from the junction to inlet air jet temperature. This is obtained by multiplying the heat rate with the sum of thermal resistances in Equation (15).

$$
T_{\mathrm{j}}-T_{\mathrm{jet}}=Q\left(R_{\mathrm{j}-\mathrm{sp}}+R_{\mathrm{sp}-\mathrm{b}}+R_{\mathrm{b}-\mathrm{jet}}\right)
$$

The required heat sink thermal resistance for the maximum ambient temperature and LED power dissipation heat rate $Q$ can be expressed using Equation (16).

$$
R_{\mathrm{b}-\mathrm{jet}}=R_{\mathrm{total}}-\left(R_{\mathrm{j}-\mathrm{sp}}+R_{\mathrm{sp}-\mathrm{b}}\right)=\frac{\left(T_{\mathrm{j}}-T_{\mathrm{jet}}\right)}{Q}-\left(R_{\mathrm{j}-\mathrm{sp}}+R_{\mathrm{sp}-\mathrm{b}}\right)
$$

\subsection{Measurement Uncertainties}

In this study, uncertainty analysis for an individual device involved in experimental measurement is described as follows. The uncertainty analysis is determined using the method by Moffat (1982) [13], Wang and Simon (1989) [14], and Yan and Owen (2002) [15] within a confidence interval of 95\%. The instruments were calibrated. The AC power source has an uncertainty of $\pm 0.5 \%$. The J-type thermocouples are calibrated to within $\pm 0.3^{\circ} \mathrm{C}$ for the range of testing temperature. Thus, the accuracy of anemometer is within $\pm 3.0 \%$ for the range of tested velocities. The average uncertainty of $h$ is $\pm 3.5 \%$ with a maximum uncertainty of $\pm 5.4 \%$.

\section{Results and Discussion}

Section 5.1 presents the numerical results which comprise the results of velocity and temperature fields. Section 5.2 elaborates the experimental results. Surface interruptions, roughened surfaces, and surface protuberances were considered for enhancing the heat transfer. These design parameters enable flow interactions over the perforations with each other and generate turbulent flows to enhance the convection heat transfer rate. Slits or offset fin interruptions were used for interrupting the boundary layer, which reshape the boundary layer and then create secondary flows to ensure the heat transfer surface with protuberance can generate secondary or unsteady flows of vortex to promote heat transfer enhancement. According to Newton's cooling law, increasing the heat transfer area or heat transfer coefficient enhances the heat transfer rate for a particular temperature difference (Chein et al. 2009) [16]. The jet impingement cooling effectively increases the heat transfer coefficient. The heat transfer performance improves with increasing Reynolds number. Aforementioned effects are numerically illustrated in Figure 7a-i and Tables 3-5 as well as Figure 8a-i and Tables 6-8 for experiments. 
Table 3. Numerical results of heat sinks with LED, fan velocity $=6.13 \mathrm{~m} \mathrm{~s}^{-1}, \operatorname{Re}=14,916$.

\begin{tabular}{ccccccc}
\hline Case & Type & $\begin{array}{c}\boldsymbol{T}_{\text {sp }} \\
\left({ }^{\circ} \mathbf{C}\right)\end{array}$ & $\begin{array}{c}\boldsymbol{T}_{\text {jet }} \\
\left({ }^{\circ} \mathbf{C}\right)\end{array}$ & $\begin{array}{c}\boldsymbol{h} \\
\left(\mathbf{W ~ m ~}^{-\mathbf{2}} \mathbf{k}^{-\mathbf{1}}\right)\end{array}$ & $\boldsymbol{N u}$ & $\begin{array}{c}\boldsymbol{R}_{\text {sp-jet }} \\
\left(\mathbf{K ~ W ~ W}^{-\mathbf{1}} \mathbf{)}\right.\end{array}$ \\
\hline 1 & TTFHS & 38.9 & 25.0 & 728.298 & 1068.545 & 1.85 \\
2 & PTFHS & 33.3 & 25.0 & 811.532 & 1190.665 & 1.11 \\
3 & MFLHS & 37.1 & 25.0 & 788.989 & 1157.591 & 1.61 \\
\hline
\end{tabular}

Table 4. Numerical results of heat sink with LED, fan velocity $=2.71 \mathrm{~m} \mathrm{~s}^{-1}, \operatorname{Re}=6594$.

\begin{tabular}{ccccccc}
\hline Case & Type & $\begin{array}{c}\mathbf{T}_{\text {sp }} \\
\left({ }^{\circ} \mathbf{C}\right)\end{array}$ & $\begin{array}{c}\boldsymbol{T}_{\text {jet }} \\
\left({ }^{\circ} \mathbf{C}\right)\end{array}$ & $\begin{array}{c}\boldsymbol{h} \\
\left(\mathbf{W ~ m ~}^{-\mathbf{2}} \mathbf{k}^{\mathbf{- 1}}\right)\end{array}$ & $\boldsymbol{N u}$ & $\begin{array}{c}\boldsymbol{R}_{\text {sp-jet }} \\
\left(\mathbf{K ~ W ~ W}^{-\mathbf{1}}\right)\end{array}$ \\
\hline 1 & TTFHS & 39.3 & 25.0 & 420.794 & 633.275 & 1.91 \\
2 & PTFHS & 38.5 & 25.0 & 511.777 & 770.199 & 1.80 \\
3 & MFLHS & 38.7 & 25.0 & 454.458 & 683.937 & 1.83 \\
\hline
\end{tabular}

Table 5. Numerical results of heat sink with LED and housing, fan velocity $=6.13 \mathrm{~m} \mathrm{~s}^{-1}, \operatorname{Re}=14,916$.

\begin{tabular}{ccccc}
\hline Case & Type & $\begin{array}{c}\boldsymbol{T}_{\text {sp }} \\
\left({ }^{\circ} \mathbf{C}\right)\end{array}$ & $\begin{array}{c}\boldsymbol{T}_{\text {jet }} \\
\left({ }^{\circ} \mathbf{C}\right)\end{array}$ & $\begin{array}{c}\boldsymbol{R}_{\text {sp-jet }} \\
\left(\mathbf{K ~ W ~}^{-1}\right)\end{array}$ \\
\hline 7 & TTFHS & 44.9 & 25.0 & 2.65 \\
8 & PTFHS & 39.4 & 25.0 & 1.92 \\
9 & MFLHS & 41.5 & 25.0 & 2.20 \\
\hline
\end{tabular}

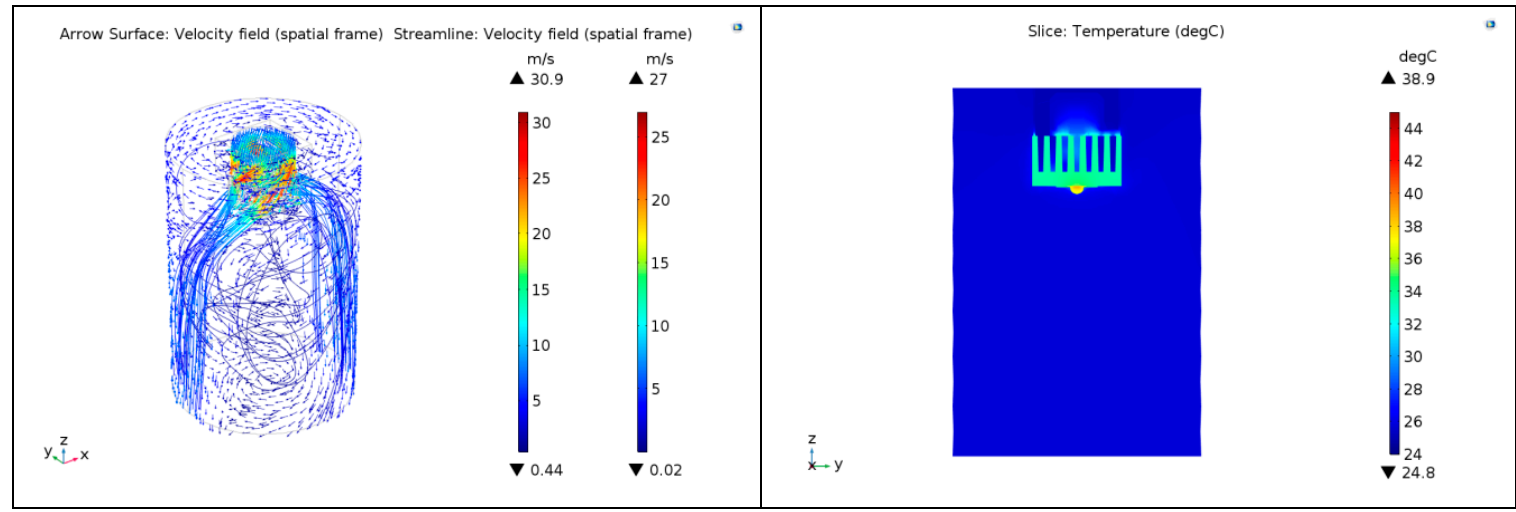

(a)

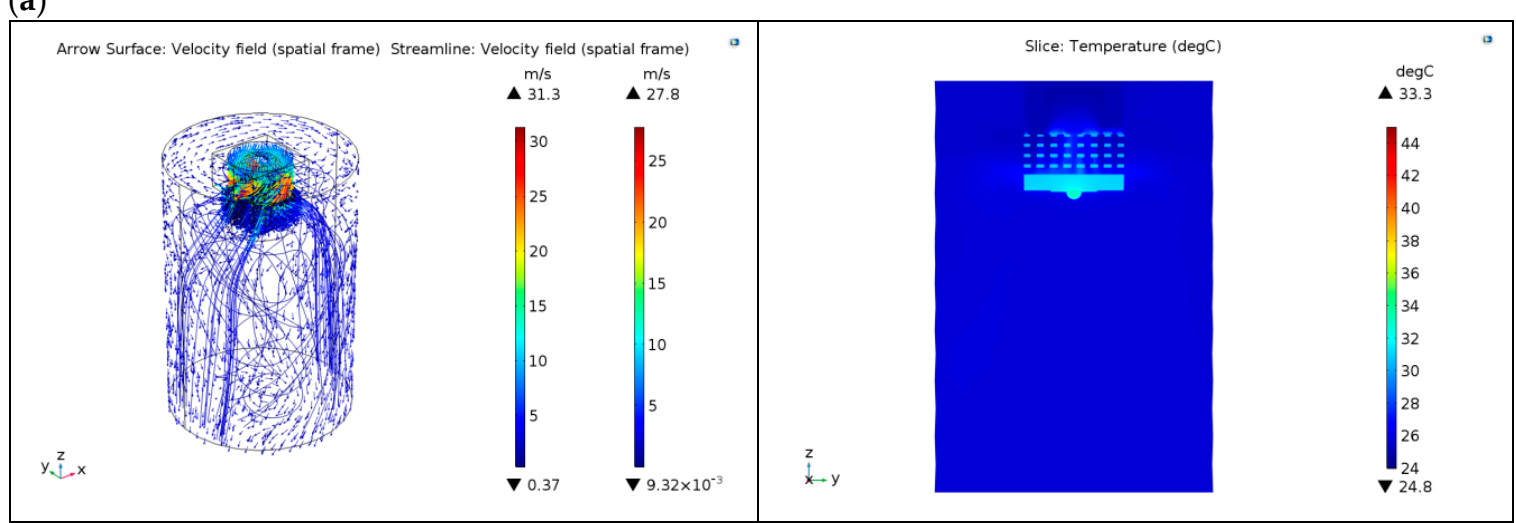

(b)

Figure 7. Cont. 


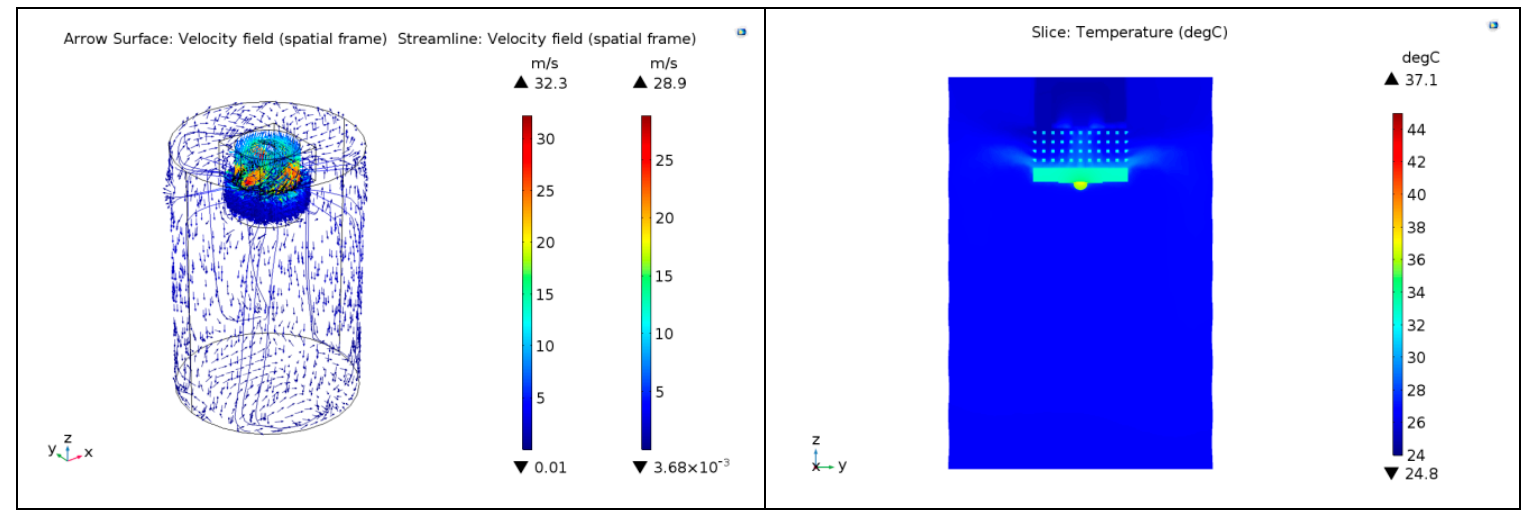

(c)

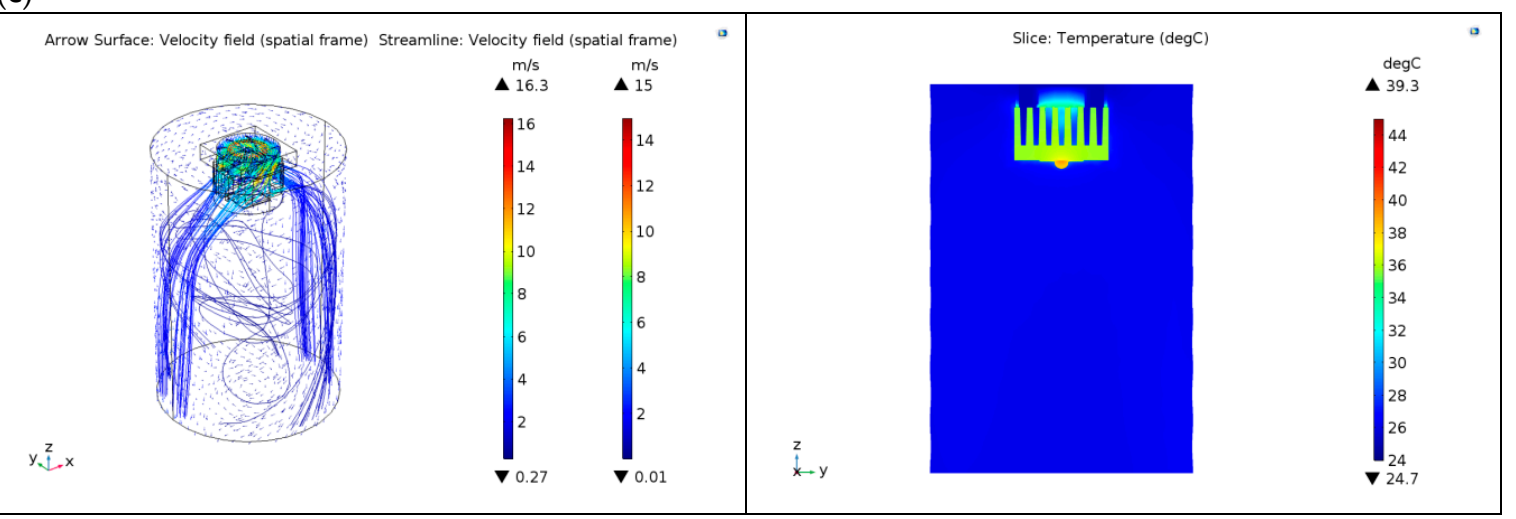

(d)

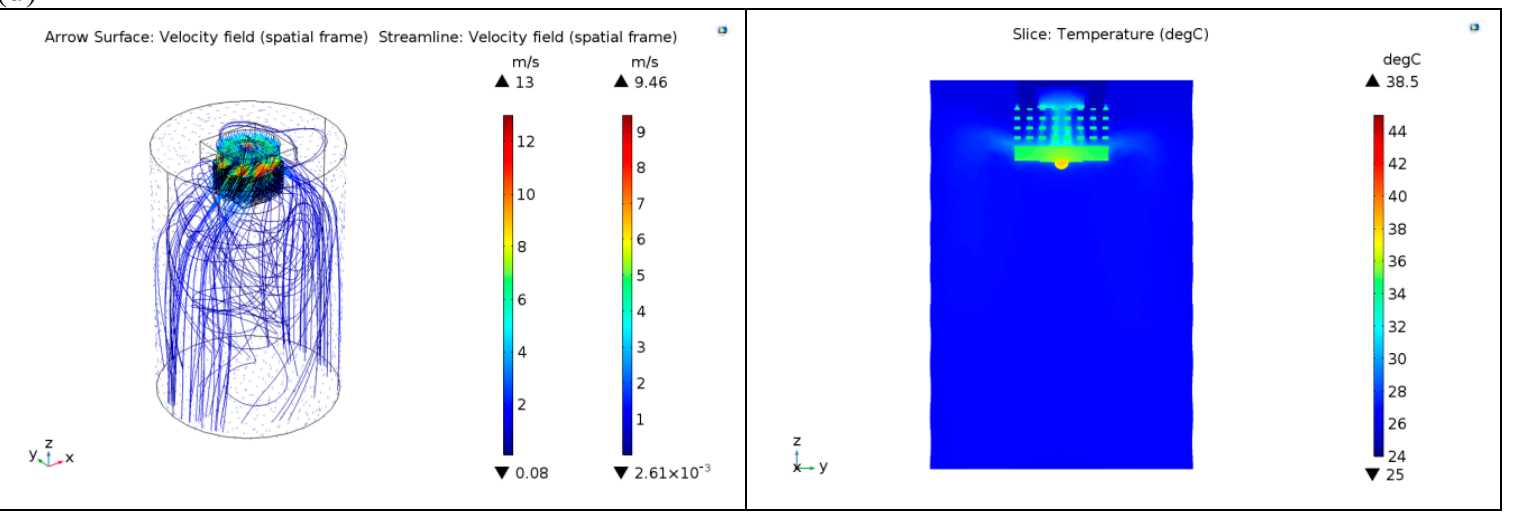

(e)

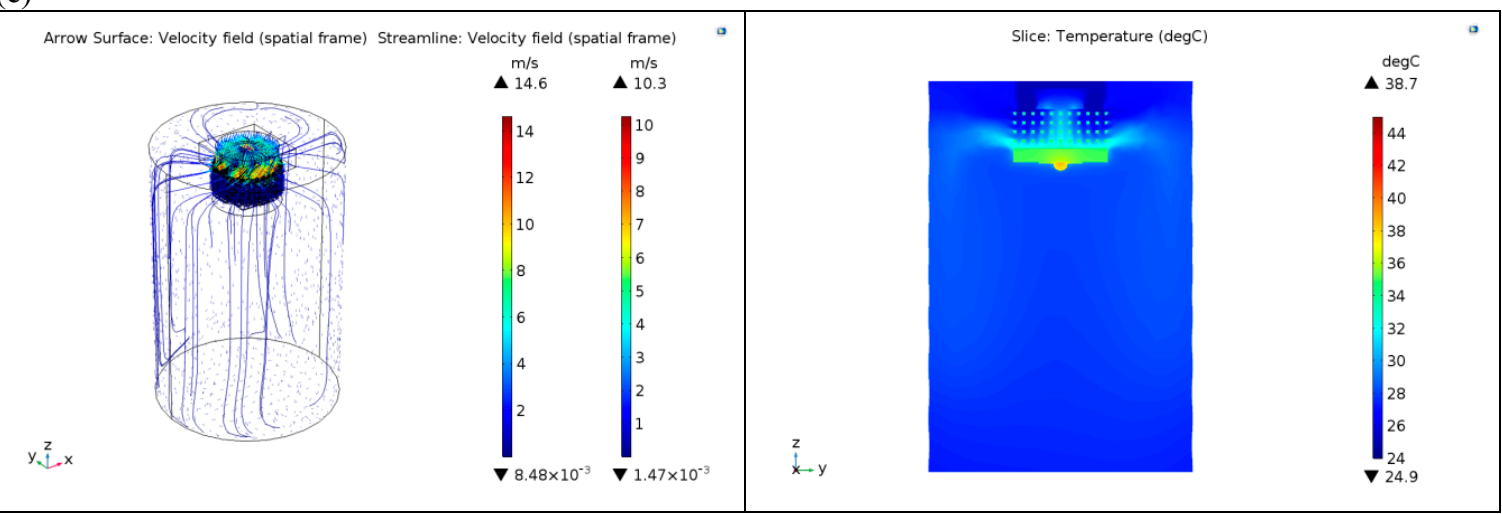

(f)

Figure 7. Cont. 

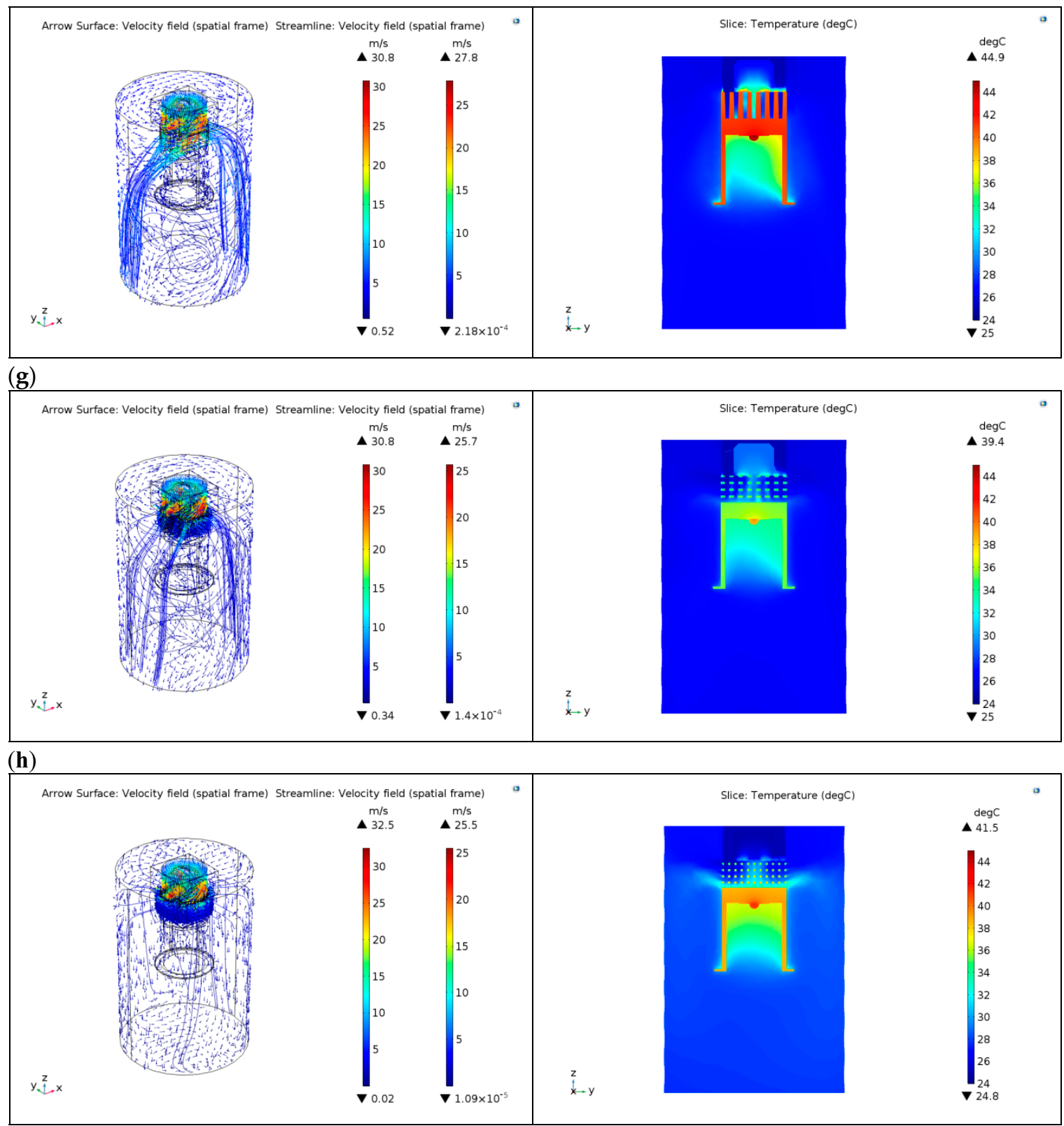

(i)

Figure 7. Numerical results of (a) case 1, (b) case 2, (c) case 3, (d) case 4, (e) case 5, (f) case 6, (g) case 7, (h) case 8, (i) case 9.

\subsection{Numerical Results}

\subsubsection{Numerical Results of Velocity Field}

Figure 7a-i depicts numerical results of cases 1-3 for TTFHS, PTFHS, and MFLHS with LED under an inlet velocity of $6.13 \mathrm{~m} \mathrm{~s}^{-1}$; cases $4-6$ for the heat sinks with LED under an inlet velocity of 2.71 $\mathrm{m} \mathrm{s}^{-1}$; and cases 7-9 for the heat sinks with LED and housing under an inlet velocity of $6.13 \mathrm{~m} \mathrm{~s}^{-1}$, respectively. In Figure $7 \mathrm{a}-\mathrm{c}$, the left plot shows velocity fields (represented by the streamline using an isometric view), whereas the right plot depicts the temperature field (represented by a front-view slice from cylindrical domain). Under different inlet velocities, all heat sinks with various thermophysical characteristics can be described using the arrow vector plots and streamline profiles. The flow patterns of the three heat sinks under different inlet velocity are considerably different as indicated by the isometric view for cases 1-9. In the isometric views presented in Figure 7a-c, the arrows indicate 
flow direction, which is rotating along the z-axis. A displacement of the fan in the negative direction produces a rotation of velocity field in the positive direction.

The arrow patterns, for the case studies 3, 6, and 9 in Figure 7c,f,i, respectively, represent the velocity vector rotating toward the center uniformly, because the pattern derived from MFLHS is a symmetric structure along the $x-z$ and $y-z$ planes. However, in Figure $7 a, b, d, e, g, h$, the velocity vector is rotating along the z-axis. This occurs because the pattern derived from TTFHS or PTFHS is a symmetric structure along the $x-z$ plane.

Streamline visualization plays a critical role in understanding the complex flow mechanism. As shown in Figure 7a-i, the streamline plots indicate that the flow passes through fan channels with high speed jet impinging onto heat sink surfaces. Comparing the jet impingement cooling performance among the investigation schemes (Table 1), the PTFHS exhibited the highest cooling performance followed by MFLHS and TTFHS because in the plots derived from TTFHS the streamline only pass through the $x-z$ plane, whereas the PTFHS streamline not only passes through the $x-z$ plane but also the $y$-z plane in the plots. The performance of MFLHS was less than that of PTFHS because even though the streamline passed through the $x-z$ and $y-z$ planes, it passed through fewer streamlines. Thus, the heat sink with horizontal perforated holes possessed higher heat transfer capability.

As a result, under higher inlet velocity, all heat sinks exhibited higher velocity magnitude than that under lower inlet velocity. This implied that higher Reynolds number increased the heat transfer rate.

\subsubsection{Numerical Results of Temperature Field}

The plots of temperature in Figure 7a-i (Tables 3-5) indicate that the PTFHS exhibited the lowest $T_{\mathrm{sp}}$, followed by MFLHS and TTFHS. As the geometries were complex, the edge lines of the solid parts in all temperature field plots were hidden for easily visualizing the plot with the altered color range. Each of the heat sinks under higher Reynolds numbers exhibited higher heat transfer performance than under a lower Reynolds number.

\subsection{Experimental Results}

The experimental results, as tabulated in Tables $6-8$, indicate that the heat sinks of TTFHS, PTFHS, and MFLHS with LED at Reynolds number 14,916 exhibited higher heat transfer coefficients $(h)$, and therefore, higher Nusselt number $(\mathrm{Nu})$, and lower thermal resistance $(R)$ than that at Reynolds number 6594. From experimental results, PTFHS exhibited the highest heat dissipation performance, followed by MFLHS and TTFHS because of the higher heat transfer coefficients and Nusselt number and lower thermal resistance and the increased surface area caused by perforations and the generated turbulent flow.

Table 6. Experimental validation results of cases 1-3 for TTFHS, PTFHS, and MFLHS with LED under inlet velocity of $6.13 \mathrm{~m} \mathrm{~s}^{-1}, \operatorname{Re}=14916$.

\begin{tabular}{|c|c|c|c|c|c|c|c|c|c|c|}
\hline Case & Type & $\begin{array}{c}T_{\mathrm{sp}} \\
\left({ }^{\circ} \mathrm{C}\right)\end{array}$ & $\begin{array}{c}T_{\mathbf{b}} \\
\left({ }^{\circ} \mathrm{C}\right)\end{array}$ & $\begin{array}{c}T_{\mathrm{hs}} \\
\left({ }^{\circ} \mathrm{C}\right)\end{array}$ & $\begin{array}{l}T_{\text {jet }} \\
\left({ }^{\circ} \mathrm{C}\right)\end{array}$ & $\begin{array}{c}D \\
(\mathrm{~m})\end{array}$ & $\begin{array}{c}A_{\mathrm{b}} \\
\left({ }^{\circ} \mathrm{C}\right)\end{array}$ & $\begin{array}{c}h \\
\left(W \mathrm{~m}^{-2} \mathrm{k}^{-1}\right)\end{array}$ & $N u$ & $\begin{array}{c}R_{\text {sp-jet }} \\
\left(\mathrm{KW}^{-1}\right)\end{array}$ \\
\hline 1 & TTFHS & 39.1 & 32.8 & 30.8 & 25.0 & 0.038 & 0.00132 & 728.298 & 1068.545 & 1.88 \\
\hline 2 & PTFHS & 33.7 & 32.0 & 29.1 & 25.0 & 0.038 & 0.00132 & 811.532 & 1190.665 & 1.16 \\
\hline 3 & MFLHS & 37.6 & 32.2 & 29.0 & 25.0 & 0.038 & 0.00132 & 788.989 & 1157.591 & 1.68 \\
\hline
\end{tabular}

Table 7. Experimental validation results of cases 4-6 for TTFHS, PTFHS, and MFLHS with LED under inlet velocity of $2.71 \mathrm{~m} \mathrm{~s}^{-1}, \operatorname{Re}=6594$.

\begin{tabular}{|c|c|c|c|c|c|c|c|c|c|c|}
\hline Case & Type & $\begin{array}{l}T_{\mathrm{sp}} \\
\left({ }^{\circ} \mathrm{C}\right)\end{array}$ & $\begin{array}{l}T_{\mathrm{b}} \\
\left({ }^{\circ} \mathrm{C}\right)\end{array}$ & $\begin{array}{l}T_{\mathrm{hs}} \\
\left({ }^{\circ} \mathrm{C}\right)\end{array}$ & $\begin{array}{l}T_{\text {jet }} \\
\left({ }^{\circ} \mathrm{C}\right)\end{array}$ & $\begin{array}{c}D \\
(\mathrm{~m})\end{array}$ & $\begin{array}{l}A_{\mathrm{b}} \\
\left({ }^{\circ} \mathrm{C}\right)\end{array}$ & $\begin{array}{c}h \\
\left(\mathrm{~W} \mathrm{~m} \mathrm{~m}^{-2} \mathrm{k}^{-1}\right)\end{array}$ & $N u$ & $\begin{array}{c}R_{\mathrm{sp}-\mathrm{jet}} \\
\left(\mathrm{K} \mathrm{W}^{-1}\right)\end{array}$ \\
\hline 4 & TTFHS & 39.6 & 38.5 & 33.0 & 25.0 & 0.038 & 0.00132 & 420.794 & 633.275 & 1.95 \\
\hline 5 & PTFHS & 38.8 & 36.1 & 33.5 & 25.0 & 0.038 & 0.00132 & 511.777 & 770.199 & 1.84 \\
\hline 6 & MFLHS & 39.4 & 37.5 & 32.4 & 25.0 & 0.038 & 0.00132 & 454.458 & 683.937 & 1.92 \\
\hline
\end{tabular}


Table 8. Experimental validation results of cases 7-9 for TTFHS, PTFHS, and MFLHS with LED and housing under inlet velocity of $6.13 \mathrm{~m} \mathrm{~s}^{-1}, \mathrm{Re}=14916$.

\begin{tabular}{cccccccc}
\hline Case & Type & $\begin{array}{c}\boldsymbol{T}_{\mathbf{s p}} \\
\left({ }^{\circ} \mathbf{C}\right)\end{array}$ & $\begin{array}{c}\boldsymbol{T}_{\mathbf{b}}{ }^{\prime} \\
\left({ }^{\circ} \mathbf{C}\right)\end{array}$ & $\begin{array}{c}\boldsymbol{T}_{\text {hs }} \\
\left({ }^{\circ} \mathbf{C}\right)\end{array}$ & $\begin{array}{c}\boldsymbol{T}_{\text {jet }} \\
\left({ }^{\circ} \mathbf{C}\right)\end{array}$ & $\begin{array}{c}\boldsymbol{T}_{\text {trim }} \\
\left({ }^{\circ} \mathbf{C}\right)\end{array}$ & $\begin{array}{c}\boldsymbol{R}_{\text {sp-jet }} \\
\left(\mathbf{K ~ W}^{-1} \mathbf{1}\right)\end{array}$ \\
\hline 7 & TTFHS & 45.3 & 33.8 & 33.6 & 25.0 & 32.9 & 2.71 \\
8 & PTFHS & 39.9 & 32.8 & 30.3 & 25.0 & 32.5 & 1.99 \\
9 & MFLHS & 42.0 & 32.3 & 30.1 & 25.0 & 32.0 & 2.27 \\
\hline
\end{tabular}

Figure $8 \mathrm{a}-\mathrm{f}$ provides the temperature profiles of the experimental results for the temperature distribution at the $T_{\mathrm{sp}}, T_{\mathrm{b}}$, and $T_{\mathrm{hs}}$ points, as well as the calculation of $T_{\mathrm{j}}$ for cases $1-3$ and cases $4-6$, respectively. Figure $8 \mathrm{~g}-\mathrm{i}$ provides the temperature profiles of the experimental results for the temperature distribution at the $T_{\mathrm{sp}}, T_{\mathrm{b}^{\prime}}, T_{\mathrm{hs}}$, and $T_{\text {trim }}$ points, as well as the calculation of $T_{\mathrm{j}}$ for cases 7-9. The steady-state temperature for each case is presented in Tables 6-8. As depicted in Figure $8 \mathrm{a}-\mathrm{i}$, the transient response of temperature rise under jet impingement cooling is fast and reaches the steady state for the first $25 \mathrm{~min}$ after powering on. The test duration time was $120 \mathrm{~min}$.

Each heat sink in different conditions exhibits various temperature distributions, such as comparisons between cases 1 and 4 , or cases 2 and 5, or cases 3 and 6 . The results indicate that a higher Reynolds number results in lower $T_{\mathrm{sp}}$. Moreover, comparing between cases 1 and 7 , or cases 2 and 8 , or cases 3 and 9 , the results indicate that the heat sink with housing exhibited increased $T_{\mathrm{sp}}$ because the thermal resistance increased due to their longer heat dissipation paths.

In cases 7-9, $T_{\text {trim }}$ was lower than $T_{\mathrm{sp}}$ because of the thermal resistance. The correlation between $T_{\text {trim }}$ and $T_{\mathrm{sp}}$ can be determined using thermal resistance equations. Therefore, $T_{\mathrm{j}}$ can be predicted using the thermal resistance model by using the measured temperature at a reference point of $T_{\text {trim }}$.

Figure $9 \mathrm{a}, \mathrm{b}$ as well as Table 9 demonstrate that the heat transfer coefficient and Nusselt number increased with the inlet velocity. The highest heat transfer coefficient was achieved by the PTFHS, followed by MFLHS and TTFHS. Figure 9a,b indicates that the PTFHS exhibits the highest heat transfer performance, followed by MFLHS and TTFHS in the lower or higher Reynolds number turbulent air flow, because the PTFHS exhibits increased heat transfer surface area and less air flow obstruction.

Figure 10a illustrates the experimental results of the thermal resistance for cases 1-9 based on Tables 6-8. The groups A, B, and C denote cases 1-3, 4-6, and 7-9, respectively. In all cases, the PTFHS exhibits the highest heat dissipation performance, followed by MFLHS and TTFHS. The optimal geometry effect enhances heat transfer. Moreover, thermal resistance difference among heat sinks are remarkable at a high inlet velocity.

The experimental results in Figure 10b-d were compared with numerical simulations for thermal resistance. Thermal resistance of TTFHS in Figure 10b is based on the case studies of higher inlet velocity, lower inlet velocity, and additional housing which denoted as groups $\mathrm{D}, \mathrm{E}$, and F, respectively. Figure 10c denotes thermal resistance of PTFHS on case studies of high inlet velocity, low inlet velocity, and additional housing which denoted as groups G, H, and I, respectively. Figure 10d denotes MFLHS for the cases studies of higher inlet velocity, lower inlet velocity, and additional housing denoted as groups J, K, and L, respectively.

Based on the comparisons, the experimental results concur with the numerical simulation results. 


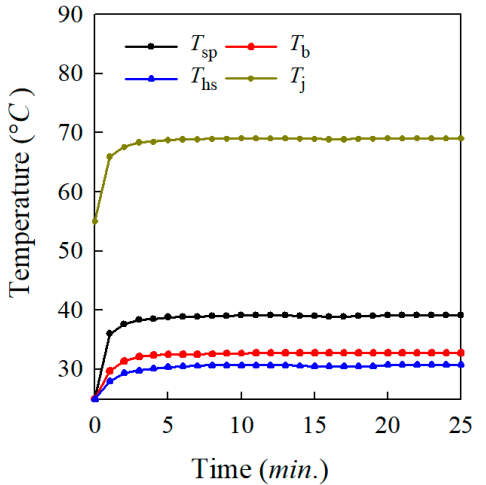

(a) case 1: TTFHS $6.13 \mathrm{~m} \mathrm{~s}^{-1}$

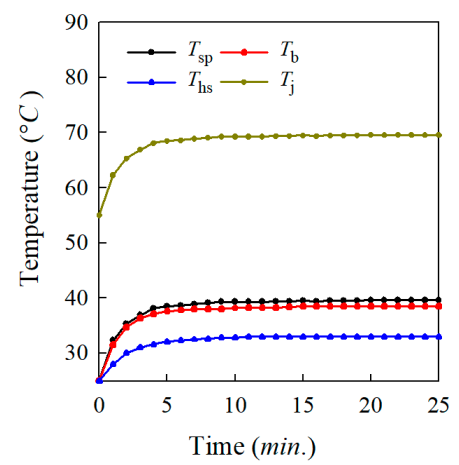

(d) case 4: TTFHS $2.71 \mathrm{~m} \mathrm{~s}^{-1}$

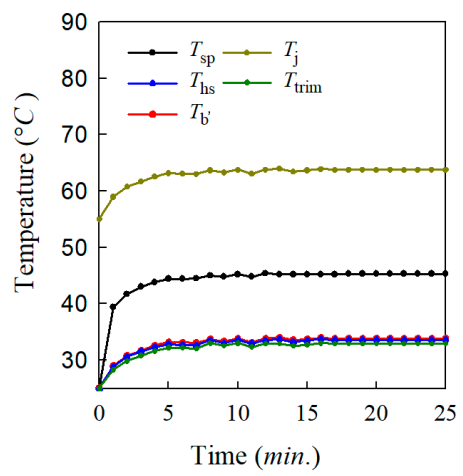

(g) case 7: TTFHS $6.13 \mathrm{~m} \mathrm{~s}^{-1}$

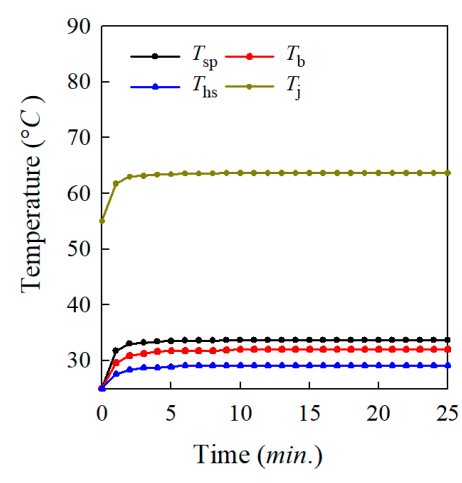

(b) case 2: PTFHS $6.13 \mathrm{~m} \mathrm{~s}^{-1}$

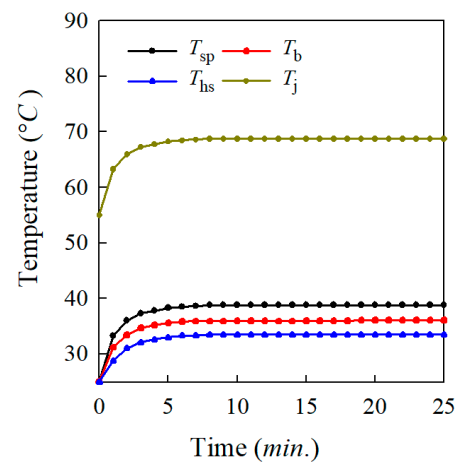

(e) case 5: PTFHS $2.71 \mathrm{~m} \mathrm{~s}^{-1}$

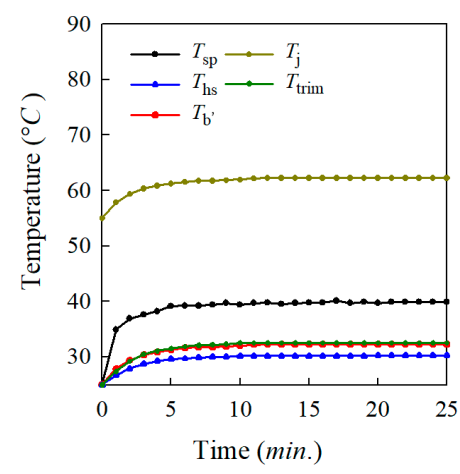

(h) case 8: PTFHS $6.13 \mathrm{~m} \mathrm{~s}^{-1}$

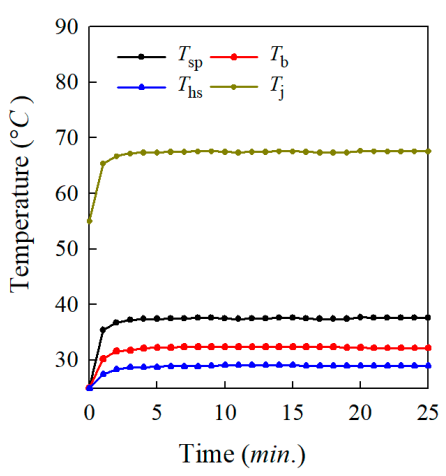

(c) case 3: MFLHS $6.13 \mathrm{~m} \mathrm{~s}^{-1}$

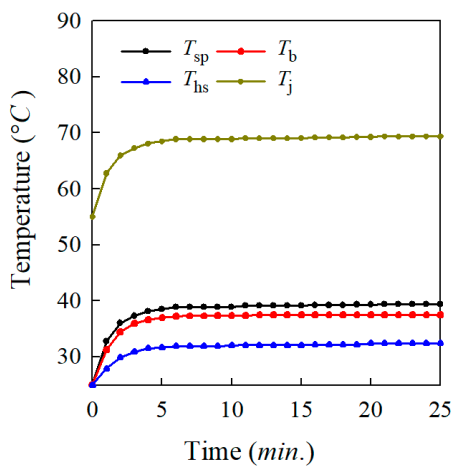

(f) case 6: MFLHS $2.71 \mathrm{~m} \mathrm{~s}^{-1}$

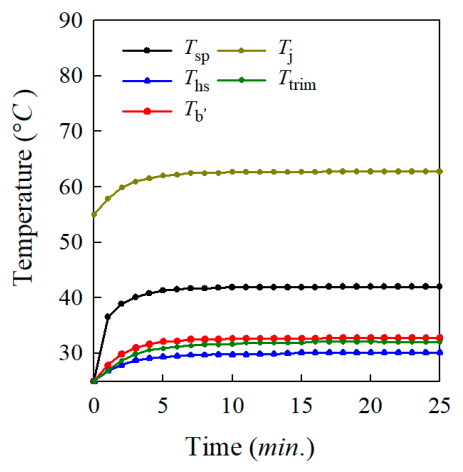

(i) case 9: MFLHS $6.13 \mathrm{~m} \mathrm{~s}^{-1}$

Figure 8. Temperature rise test results of cases 1-9.

Table 9. Nusselt number increase, thermal resistance reduction and weight reduction comparing PTFHS and MFLHS with TTFHS.

\begin{tabular}{ccc}
\hline Heat Sink Type & PTFHS & MFLHS \\
\hline Nusselt number increase, \% & 10.3 & 7.7 \\
Thermal resistance reduction, \% & 40.3 & 13.0 \\
Weight reduction, \% & 23.6 & 24.6 \\
\hline
\end{tabular}




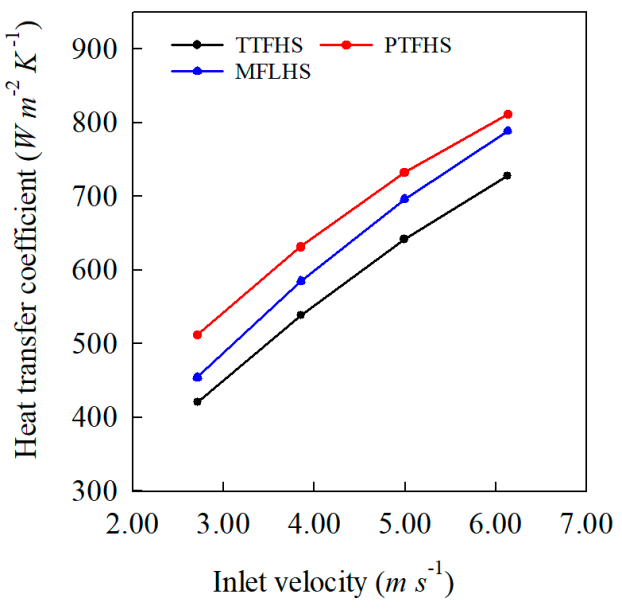

(a)

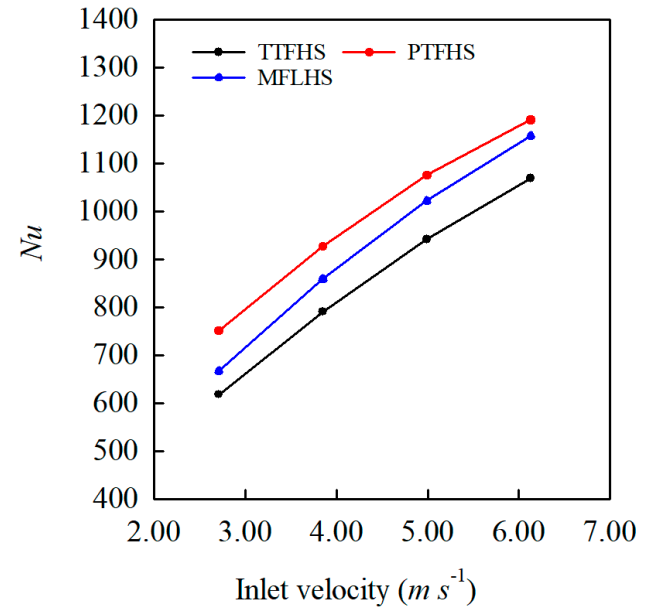

(b)

Figure 9. Effect of inlet velocity on (a) heat transfer coefficient, (b) Nusselt number for different heat sinks.

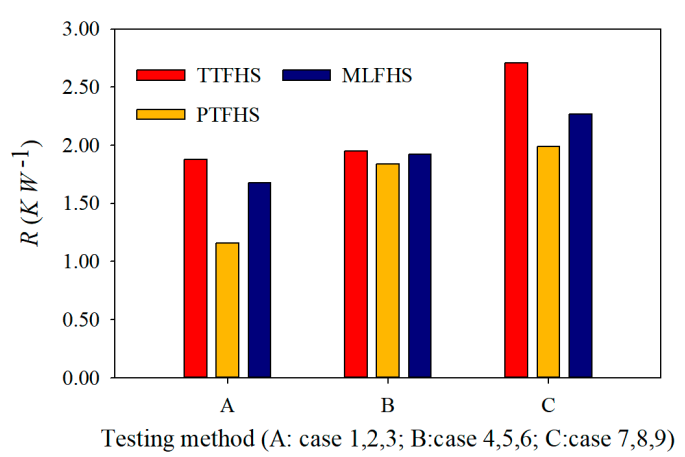

(a)

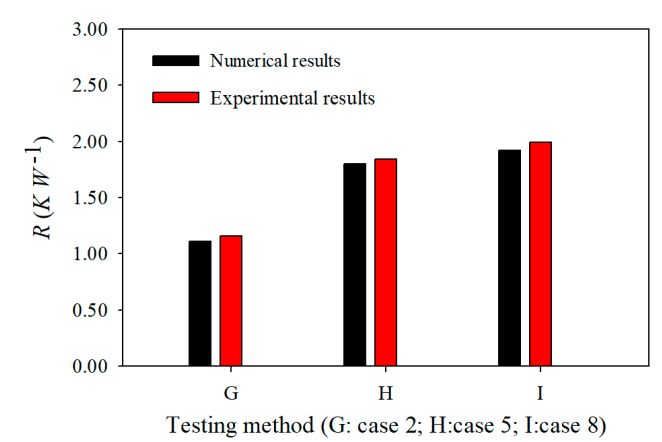

(c)

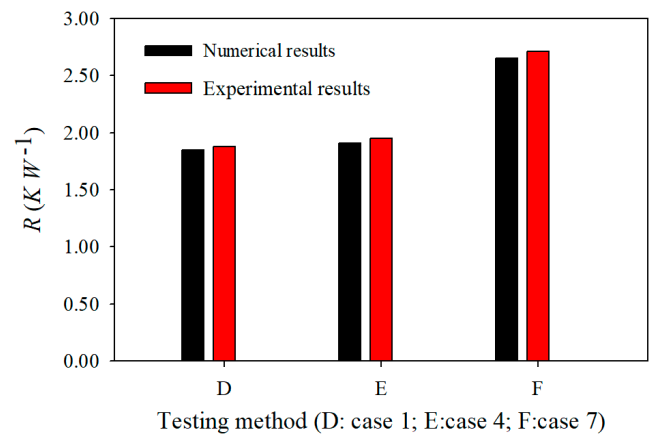

(b)

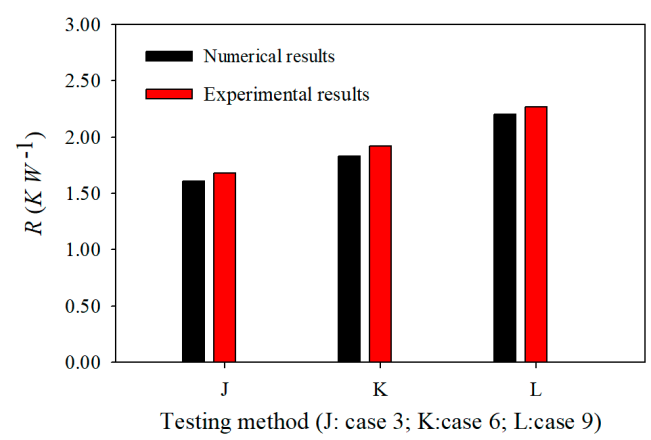

(d)

Figure 10. Thermal resistance comparison, (a) experimental validation for cases 1-9; comparison between experimental and numerical prediction for (b) TTFHS, (c) PTFHS, and (d) MFLHS.

\subsection{Effects of Nusselt Number, Thermal Resistance Reduction, and Weight Reduction}

A large Nusselt number for enhancing heat transfer rate in addition to a decrease in thermal resistance and light weight of SLM heat sinks are vital for residential, commercial, and industrial lighting applications. Considerable heat sink weight reduction facilitates fast manufacturing and reduced material cost. Table 9 indicates the effects of a higher Nusselt number, thermal resistance reduction, and weight reduction for the PTFHS and MFLHS compared with the TTFHS. 


\subsection{Allowable Increasing Temperature Difference for Existing CLRDL Using Relatively Higher Power LEDs}

In Table 10, experimental results indicate that the LED's junction temperature allowance is enlarged downward from the specified limited temperature of $135^{\circ} \mathrm{C}$. Since the proposed heat sinks of the PTFHS and MFLHS under jet impingement cooling have considerable reduced junction temperature of the $10 \mathrm{~W}$ LED CLRDL. Therefore, it allowed the CLRDL to increase LED power higher than $10 \mathrm{~W}$ for higher light output requirement. The previous studies (Hsu and Huang 2016; Huang and Hsu 2018) $[9,10]$ have shown that for the LED junction temperature at approximately $120^{\circ} \mathrm{C}$, with the CLRDL in the enclosed test box under natural convection, the temperature allowance ranged from 120 to $135^{\circ} \mathrm{C}$ (approximate difference of only $15^{\circ} \mathrm{C}$ ). Nevertheless, in this study, the heat sinks under jet impingement cooling could maintain a considerably lower LED junction temperature. The allowable increasing temperature difference of the LED junction temperature ranged from 69.4 to $135^{\circ} \mathrm{C}$ for PTFHS and from 71.5 to $135{ }^{\circ} \mathrm{C}$ for MFLHS. The temperature allowance enlarged up to 65.6 and $63.5^{\circ} \mathrm{C}$, respectively. The increasing rate was approximately $337.3 \%$ and $323.3 \%$, respectively. This proved that the CLRDL was allowed to increase the LED power higher than $10 \mathrm{~W}$, where the junction temperature is limited to $135^{\circ} \mathrm{C}$. Thus, higher light output requirement can be achieved.

Table 10. Temperature allowance for CLRDL when using relatively higher power levels LED.

\begin{tabular}{ccccc}
\hline Type & $\begin{array}{c}\boldsymbol{T}_{\mathbf{s p}} \\
\left({ }^{\circ} \mathbf{C}\right)\end{array}$ & $\begin{array}{c}\boldsymbol{T}_{\mathbf{j}} \\
\left({ }^{\circ} \mathbf{C}\right)\end{array}$ & $\begin{array}{c}\text { Specified LED Limited } \boldsymbol{T}_{\mathbf{j}} \\
\left({ }^{\circ} \mathbf{C}\right)\end{array}$ & $\begin{array}{c}\text { Allowance of } \boldsymbol{T}_{\mathbf{j}} \text { to be Increased } \\
\left({ }^{\circ} \mathbf{C}\right)\end{array}$ \\
\hline PTFHS & 39.4 & 69.4 & 135 & 65.6 \\
MFLHS & 41.5 & 71.5 & 135 & 63.5 \\
\hline
\end{tabular}

\section{Conclusions}

In this study, we first numerically investigated the improvement in heat dissipation performance using the heat sinks fabricated using SLM for a CLRDL under jet impingement cooling. An optimized surface area for TTFHS was designed as a benchmark. Nine cases were developed to examine the heat transfer coefficient, Nusselt number, and thermal resistance. Experimental tests were conducted to validate the numerical simulation results. Some detailed specified temperature points for their temperature response were also measured. Under jet impingement cooling, the inlet air flow velocity, heat transfer surface area of heat sink, and heat sink geometries are the primary factors for heat transfer performance. Some concluding remarks are reached as follows.

(1) Using the SLM approach, the PTFHS exhibited the highest heat transfer performance followed by the MFLHS and TTFHS irrespective of lower or higher Reynolds number turbulent air flow, because the PTFHS possesses increased heat transfer surface area and less air flow obstruction. Although MFLHS has increased heat transfer surface area, its heat transfer performance was less than the PTFHS because of its relatively narrow air flow channels obstructing heat exchange with the environment.

(2) The proposed PTFHS and MFLHS increased the Nusselt number by $10.3 \%$ and $7.7 \%$, reduced thermal resistance by $40.3 \%$ and $13.0 \%$, and achieved weight reduction of $23.6 \%$ and $24.6 \%$, respectively, based on comparisons of TTFHS. This enhanced the heat transfer rate and reduced the LED lighting module weight. Therefore, it allowed the CLRDL to increase LED power higher than $10 \mathrm{~W}$ for further light output requirement.

(3) This study contributes to the applications of small or narrow spaces and a large heat removal requirement by applying jet impingement cooling. The numerical simulation results were consistent with experimental results. This consistency validated the approach of using the CLRDLs with PTFHS, MFLHS, and TTFHS under an environment with a high heat-source temperature and maintaining a low LED's junction temperature for ensuring LEDs longer lifetimes specified by Energy Star. 
Author Contributions: Conceptualization, Y.-C.H. and H.-C.H.; Formal analysis, Y.-C.H. and H.-C.H.; Investigation, Y.-C.H. and H.-C.H.; Methodology, Y.-C.H. and H.-C.H.; Software, Y.-C.H. and H.-C.H.; Validation, Y.-C.H. and H.-C.H.; Writing-original draft, Y.-C.H. and H.-C.H.; Writing-review and editing, Y.-C.H. and H.-C.H. All authors have read and agreed to the published version of the manuscript.

Funding: Partial financial support from the MOST 108-2221-E-018-013 is appreciated.

Acknowledgments: The authors would like to acknowledge the manufacturing of SLM (PTFHS and MFLHS) made of AlSi10Mg alloy from the Laser and Additive Manufacturing Technology Center, Industrial Technology Research Institute.

Conflicts of Interest: The authors declare no conflict of interest.

\section{Nomenclature}

A

$A_{\mathrm{b}}$

$C_{\mathrm{p}}$

$D$

F

$g$

$h$

$h_{\mathrm{m}}$

$\bar{h}$

I

$I_{\mathrm{f}}$

$k$

$k$

$L_{\mathrm{c}}$

$\mathrm{Nu}$

$p$

$r_{b p}$

Q

$q^{\prime \prime}$

Re

$R$

$R_{\mathrm{b} \text {-jet }}$

$R_{\mathrm{j} \text {-jet }}$

$R_{\mathrm{j} \text {-sp }}$

$R_{\text {sp-hs }}$

$R_{\mathrm{sp}-\mathrm{b}}$

$R_{\text {sp-jet }}$

$R_{\mathrm{sp}-\text { trim }}$

$T$

$T$

$T_{\mathrm{a}}$

$T_{\mathrm{b}}$

$T_{\mathrm{h}}$

$T_{\text {hs }}$

$T_{\mathrm{j}}$

$T_{\text {jet }}$

$T_{\mathrm{sp}}$

$T_{\text {trim }}$

$t$

$t^{*}$

$u$

$\bar{u}$

$V_{\mathrm{f}}$

$w$
Area

Area of heat sink base

Specific heat at constant pressure

Inlet jet hole diameter

Volume force

Gravity, $9.8 \mathrm{~m} \mathrm{~s}^{-2}$

Convective heat transfer coefficient

Modified convective heat transfer coefficient

Average heat transfer coefficient

Identity matrix

LED forward current

Thermal conductivity

Turbulent kinetic energy

Characteristic length

Nusselt number

Pressure

Rotation axis base point (present study keeps it zero, constants)

Heat generation per volume, heat dissipation rate

Heat flux

Reynolds number

Thermal resistance

Thermal resistance of heatsink base to inlet air jet temperature

Thermal resistance of junction to inlet air jet temperature

Thermal resistance of junction to solder point

Thermal resistance of solder point to heatsink

Thermal resistance of solder point to heatsink base

Thermal resistance of solder point to inlet air jet temperature

Thermal resistance of solder point to trim temperature

Celsius temperature

Kelvin temperature, ${ }^{\circ} \mathrm{C}+273.15^{\circ} \mathrm{C}$

Ambient temperature

Heat sink base temperature

Housing temperature

Heatsink temperature

Junction temperature

Inlet air jet temperature

Solder point temperature

Trim temperature under housing

Time

Frozen time

Velocity

Averaged velocity

LED forward voltage

Angular velocity $\mathrm{m}^{2}$

$\mathrm{m}^{2}$

$\mathrm{J} \mathrm{kg}^{-1} \mathrm{~K}^{-1}$

$\mathrm{m}$

$\mathrm{N} \mathrm{m}^{-3}$

$\mathrm{m} \mathrm{s}^{-2}$

$\mathrm{W} \mathrm{m}^{-2} \mathrm{~K}^{-1}$

$\mathrm{W} \mathrm{m}^{-2} \mathrm{~K}^{-1}$

$\mathrm{W} \mathrm{m}^{-2} \mathrm{~K}^{-1}$

$\mathrm{mA}$

$\mathrm{W} \mathrm{m}^{-1} \mathrm{~K}^{-1}$

$\mathrm{m}^{-2} \mathrm{~s}^{-2}$

$\mathrm{M}$

Dimensionless

$\mathrm{Pa}$

$\mathrm{W} \mathrm{m}^{-3}$

$\mathrm{W} \mathrm{\textrm {m } ^ { - 2 }}$

Dimensionless

$\mathrm{KW}^{-1}$

$\mathrm{KW}^{-1}$

$\mathrm{KW}^{-1}$

$\mathrm{KW}^{-1}$

$\mathrm{KW}^{-1}$

$\mathrm{KW}^{-1}$

$\mathrm{KW}^{-1}$

$\mathrm{KW}^{-1}$

${ }^{\circ} \mathrm{C}$

$\mathrm{K}$

${ }^{\circ} \mathrm{C}$

${ }^{\circ} \mathrm{C}$

${ }^{\circ} \mathrm{C}$

${ }^{\circ} \mathrm{C}$

${ }^{\circ} \mathrm{C}$

${ }^{\circ} \mathrm{C}$

${ }^{\circ} \mathrm{C}$

${ }^{\circ} \mathrm{C}$

$\mathrm{S}$

$\mathrm{S}$

$\mathrm{m} \mathrm{s}^{-1}$

$\mathrm{m} \mathrm{s}^{-1}$

$\mathrm{V}$

$\operatorname{rad~s}^{-1}$ 
Greek symbols

$\begin{array}{ll}\alpha & \text { Thermal diffusivity } \\ \beta & \text { Volume expansivity } \\ \varepsilon & \text { Turbulent energy dissipation rate } \\ \Delta & \text { Difference } \\ \nabla & \text { Gradient } \\ \rho & \text { Density } \\ \mu & \text { Viscosity or dynamic viscosity } \\ \nu & \text { Kinematic viscosity } \\ \omega & \text { Angular displacement } \\ \text { Superscript } & \\ T & \text { The transpose of matrix }\end{array}$

$$
\begin{aligned}
& \mathrm{m}^{2} \mathrm{~s}^{-1} \\
& \mathrm{~K}^{-1} \\
& \mathrm{~m}^{-2} \mathrm{~s}^{-2} \\
& - \\
& - \\
& \mathrm{kg} \mathrm{m}^{-3} \\
& \text { Pa.s } \\
& \mathrm{m}^{2} \mathrm{~s}^{-1} \\
& \text { Rad }
\end{aligned}
$$

\section{References}

1. COMSOL Inc. COMSOL Multiphysics 5.3, CFD Module, Software Licensed by COMSOL Inc.; Pitotech: Changhua City, Taiwan, 2017.

2. Li, H.Y.; Chiang, M.H.; Chen, K.Y. Performance analysis of pin-fin heat sinks with confined impingement cooling. IEEE Trans. Compon. Packag. Technol. 2007, 30, 383-389. [CrossRef]

3. Yang, Y.T.; Lin, S.C.; Wang, Y.H.; Hsu, J.C. Numerical simulation and optimization of impingement cooling for rotating and stationary pin-fin heat sinks. Int. J. Heat Fluid Flow 2013, 44, 383-393. [CrossRef]

4. Collins, I.L.; Weibel, J.A.; Pan, L.; Garimella, S.V. A permeable-membrane microchannel heat sink made by additive manufacturing. Int. J. Heat Mass Transf. 2019, 131, 1174-1183. [CrossRef]

5. $\quad \mathrm{Li}, \mathrm{Y} . ; \mathrm{Gu}, \mathrm{D}$. Parametric analysis of thermal behavior during selective laser melting additive manufacturing of aluminum alloy powder. Mater. Des. 2014, 63, 856-867. [CrossRef]

6. Kempen, K.; Thijs, L.; Van Humbeeck, J.; Kruth, J.P. Mechanical properties of AlSi10Mg produced by selective laser melting. Phys. Procedia 2012, 39, 439-446. [CrossRef]

7. Huang, C.H.; Chen, Y.H. An impingement heat sink module design problem in determining simultaneously the optimal non-uniform fin widths and heights. Int. J. Heat Mass Transf. 2014, 73, 627-633. [CrossRef]

8. Ong, K.; Tan, C.; Lai, K.; Tan, K. Heat spreading and heat transfer coefficient with fin heat sink. Appl. Therm. Eng. 2017, 112, 1638-1647. [CrossRef]

9. Hsu, H.C.; Huang, Y.C. Numerical simulation and experimental validation for the thermal analysis of a compact LED recessed downlight with heat sink design. Appl. Sci. 2016, 7, 4. [CrossRef]

10. Huang, Y.C.; Hsu, H.C. Numerical simulation and experimental validation of heat sinks fabricated using selective laser melting for use in a compact LED recessed downlight. Microsyst. Technol. 2018, 25, 121-137. [CrossRef]

11. Wong, M.; Owen, I.; Sutcliffe, C.; Puri, A. Convective heat transfer and pressure losses across novel heat sinks fabricated by Selective Laser Melting. Int. J. Heat Mass Transf. 2009, 52, 281-288. [CrossRef]

12. Ahn, B.; Park, J.; Yoo, S.; Kim, J.; Jeong, H.; Leigh, S.; Jang, C. Synergetic Effect between Lighting Efficiency Enhancement and Building Energy Reduction Using Alternative Thermal Operating System of Indoor LED Lighting. Energies 2015, 8, 8736-8748. [CrossRef]

13. Moffat, R.J. Contributions to the theory of single-sample uncertainty analysis. J. Fluids Eng. 1982, 104, 250-258. [CrossRef]

14. Wang, T.; Simon, T. Development of a special-purpose test surface guided by uncertainty analysis. J. Thermophys. Heat Transf. 1989, 3, 19-26. [CrossRef]

15. Yan, Y.; Owen, J. Uncertainties in transient heat transfer measurements with liquid crystal. Int. J. Heat Fluid Flow 2002, 23, 29-35. [CrossRef]

16. Chein, R.; Yang, H.; Tsai, T.H.; Lu, C. Experimental study of heat sink performance using copper foams fabricated by electroforming. Microsyst. Technol. 2009, 16, 1157-1164. [CrossRef] 